\title{
Cuticular Hydrocarbon Trails Released by Host Larvae Lose their Kairomonal Activity for Parasitoids by Solidification
}

\author{
Sarah Awater-Salendo ${ }^{1,2} \cdot$ Dagmar Voigt $^{3} \cdot$ Monika Hilker $^{2} \cdot$ Benjamin Fürstenau $^{1}$ (i)
}

Received: 23 June 2021 / Revised: 21 August 2021 / Accepted: 26 August 2021 / Published online: 16 September 2021

(c) The Author(s) 2021

\begin{abstract}
Successful host search by parasitic wasps is often mediated by host-associated chemical cues. The ectoparasitoid Holepyris sylvanidis is known to follow chemical trails released by host larvae of the confused flour beetle, Tribolium confusum, for short-range host location. Although the hexane-extractable trails consist of stable, long-chain cuticular hydrocarbons (CHCs) with low volatility, the kairomonal activity of a trail is lost two days after release. Here, we studied whether this loss of kairomonal activity is due to changes in the chemical trail composition induced by microbial activity. We chemically analyzed trails consisting of hexane extracts of $T$. confusum larvae after different time intervals past deposition under sterile and non-sterile conditions. GC-MS analyses revealed that the qualitative and quantitative pattern of the long-chain $\mathrm{CHCs}$ of larval trails did not significantly change over time, neither under non-sterile nor sterile conditions. Hence, our results show that the loss of kairomonal activity of host trails is not due to microbially induced changes of the CHC pattern of a trail. Interestingly, the kairomonal activity of trails consisting of host larval CHC extracts was recoverable after two days by applying hexane to them. After hexane evaporation, the parasitoids followed the reactivated host trails as they followed freshly laid ones. Cryo-scanning electron microscopy showed that the trails gradually formed filament-shaped microstructures within two days. This self-assemblage of CHCs was reversible by hexane application. Our study suggests that the long-chain $\mathrm{CHCs}$ of a host trail slowly undergo solidification by a self-assembling process, which reduces the accessibility of CHCs to the parasitoid's receptors as such that the trail is no longer eliciting trail-following behavior.
\end{abstract}

Keywords Bethylidae $\cdot$ Insect cuticle $\cdot$ Perception $\cdot$ Trail-following behavior $\cdot$ Tenebrionidae $\cdot$ Tribolium confusum

\section{Introduction}

Successful foraging behavior of parasitic wasps depends on recognition of host-associated cues indicating the presence and location of a potential host. On a long range, highly volatile feeding- or oviposition-induced host plant odors, as

Benjamin Fürstenau

benjamin.fuerstenau@julius-kuehn.de

1 Federal Research Centre for Cultivated Plants, Institute for Ecological Chemistry, Plant Analysis and Stored Product Protection, Julius Kühn Institute, Königin-Luise-Str.19, 14195 Berlin, Germany

2 Dahlem Centre of Plant Science, Institute of Biology, Applied Zoology/Animal Ecology, Freie Universität Berlin, Haderslebener Str.9, 12163 Berlin, Germany

3 Institute of Botany, Faculty of Biology, Technische Universität Dresden, Zellescher Weg 20b, 01217 Dresden, Germany well as volatile cues released by the host itself, may guide host searching parasitoids (Hilker and McNeil 2008; Steidle and Van Loon 2003; Vinson 1998). On a short range, chemicals of low volatility may become important for host location (Colazza et al. 2014; Vinson 1998).

Chemical trails left by host insects on the plant surface or feeding substrate were shown to consist of low volatile, long-chain cuticular hydrocarbons (CHCs) (Colazza et al. 2007; Fürstenau and Hilker 2017; Rostás and Wölfling 2009). Several parasitoid species are known to recognize and follow host trails (Colazza et al. 2009; Howard et al. 1998; Lo Giudice et al. 2011; Rostás and Wölfling 2009). These trails are used as kairomones for host location, for host recognition, and even for host gender discrimination (Borges et al. 2003; Gomes Lagôa et al. 2020; Howard and Flinn 1990; Salerno et al. 2009). In addition to trails deposited by hosts, parasitoids also react to trails released by predatory insects and by conspecifics. They respond to trails left by predators by avoidance behavior (Nakashima et al. 2004) and 
exploit trails left by conspecifics for mate finding (Bernal and Luck 2007; Kapranas et al. 2013).

CHCs of host insects chemically make up the dominant part of trails used by parasitoids (Blomquist and Bagnères 2010; Geiselhardt et al. 2009; Gomes Lagôa et al. 2020). Insects release their $\mathrm{CHCs}$ onto the substrate, which is in contact with their whole body or only their tarsi (e.g., Hasenfuss 1977; Geiselhardt et al. 2009, 2010; Gerhardt et al. 2016; Lo Giudice et al. 2011; Rostás and Wölfling 2009). In general, CHCs have several important functions in insects, ranging from protection against desiccation to the mediation of intra- and interspecific communication (e.g., Gibbs 1998; Howard and Blomquist 2005; Lockey 1988; Menzel et al. 2017; Otte et al. 2018). The multifunctionality of CHCs is based on the various types of CHCs, which can be saturated or unsaturated, linear or methyl-branched (Blomquist and Bagnères 2010; Blomquist and Ginzel 2021; Gibbs 2002). According to Menzel et al. (2019), the epicuticular layer of hydrocarbons forms a solid-liquid mixture over a broad range of temperatures due to the different melting temperatures of $\mathrm{CHC}$ types. Thus, the physical traits of $\mathrm{CHCs}$ vary with fluctuating environmental conditions to maintain the biological function of CHCs (Beament 1958; Menzel et al. 2017; Sprenger et al. 2018).

The persistence of kairomonal activity of host insect trails mediating the foraging behavior of parasitoids is limited in time, despite the low volatility of CHCs. Previous studies have shown that the kairomonal effect of host $\mathrm{CHC}$ trails on foraging larval parasitoids decreased significantly one day after trail deposition and lasted only for a maximum of three days (Fürstenau and Hilker 2017; Rostás and Wölfling 2009). The persistence of trails laid by social insects for recruitment of nestmates to resources is usually achieved by renewal of the trail as long as the resource is available. Thus, trails of social insects consisting of more volatile compounds than long-chain $\mathrm{CHCs}$ can persist for a long time but would decay within minutes if not consistently renewed (Jeanson et al. 2003; Morgan 2009; Robinson et al. 2008). However, trails left by non-social host insects of parasitoids are only renewed when the host is moving by chance on the same track where it has been before.

It is unknown so far which factors contribute to the low persistence of the kairomonal effect of host insect trails on foraging parasitoids. Microbes present on the substrate or released by host insects when depositing the trail might contribute to a change in the chemical profile of trails. Microbes living in symbiosis with insects are well known to shape the production of CHCs of their hosts (Engl and Kaltenpoth 2018; Sprenger and Menzel 2020). Entomopathogenic fungi (e.g., Beauveria bassiana ([Bals.-Criv.] Vuill., Cordy cipitaceae) and Metarhizium anisopliae ([Meschn.] Sorokin, Clavicipitaceae)) are known to metabolize CHCs as a carbon source for their growth, thereby alternating the $\mathrm{CHC}$ profiles of infected host insects (Lecuona et al. 1991; Napolitano and Juárez 1997; Pedrini et al. 2013). However, no knowledge is available on whether microorganisms are involved in the decrease of kairomonal activity of host insect trails consisting of CHCs.

Here, we addressed this gap in knowledge by studying the persistence of the chemical composition of CHC trails released by $T$. confusum (Du Val 1863) (Coleoptera: Tenebrionidae), under sterile conditions (excluding microbial activity) and non-sterile ones. The CHC trails left by larvae of this beetle are followed by the larval ectoparasitoid Holepyris sylvanidis (Bréthes 1913) (Hymenoptera: Bethylidae), which attacks larvae of several stored-product beetles, including different species of the genus Tribolium (Amante et al. 2017, 2018; Evans 1969; Fürstenau and Hilker 2017). Holepyris sylvanidis discriminates between a host and a non-host species by a specific pattern of methyl-branched alkanes. The host-specific CHC pattern is common to the cuticle of different host beetle species (Awater-Salendo et al. 2020). Hexane extracts of host larvae deposited as trails elicit trail-following behavior of $H$. sylvanidis. The kairomonal effect of $T$. confusum larval trails on $H$. sylvanidis females was shown to last for at maximum two days, although these trails are exclusively composed of long-chain, low volatile, saturated CHCs (Fürstenau and Hilker 2017).

In detail, our study investigated the following questions by analyzing CHC trails of $T$. confusum larvae extracted with hexane: (1) Does the chemical composition of trails change over time past trail deposition when microbial degradation is excluded? (2) Does the chemical composition of trails from host larval extracts, which are not excluded from microbial degradation, change over time past trail deposition? Therefore, we analyzed the quantitative and qualitative $\mathrm{CHC}$ profiles of sterile-filtered and non-filtered $\mathrm{CHC}$ trails $0 \mathrm{~h}, 24 \mathrm{~h}$, and $48 \mathrm{~h}$ after deposition by coupled gas chromatography-mass spectrometry (GC-MS). Furthermore, we asked (3) whether the kairomonal activity of $48 \mathrm{~h}$-old, inactive trails from host larval extracts can be recovered by the application of hexane and (4) whether changes in physical structures of trails from host larval extracts $1 \mathrm{~h}$ and $48 \mathrm{~h}$ past deposition can be visualized by cryo-scanning electron microscopy (cryo-SEM).

\section{Methods and Material}

\section{Insects}

Individuals of $H$. sylvanidis and $T$. confusum were taken from a permanent rearing maintained at the Institute for Ecological Chemistry, Plant Analysis and Stored Product Protection (Julius Kühn Institute, Berlin, Germany). The insects were reared on wheat grist according to a protocol 
described by Fürstenau et al. (2016). For chemical analyses of host larval trails, we used 4th instar T. confusum larvae, which represent the preferred host stage of the parasitoid (Awater-Salendo et al. 2020). For the trail-following bioassays, we used unmated, one- to five-day-old $H$. sylvanidis females without previous oviposition experience.

\section{Preparation of CHC Extracts from T. confusum Host Larvae}

Since hexane extracts of $T$. confusum larvae elicit trailfollowing behavior in female $H$. sylvanidis when freshly applied onto a substrate but lose their kairomonal activity after two days (Fürstenau and Hilker 2017), we here studied whether the chemical composition of these trails changes over time past deposition. We used hexane extracts of 4th instar larvae (hereafter referred to as "larval trails") instead of naturally laid trails by larvae for our analyses because thus the quantities of compounds detected in the trails could be exactly determined and referred to larval individuals (larval equivalents $=$ LE per volume hexane; see below).

The chemical composition of larval trails was analyzed $0 \mathrm{~h}, 24 \mathrm{~h}$, and $48 \mathrm{~h}$ after trail deposition on glass Petri dishes (for details, see below). We analyzed freshly laid trails $(0 \mathrm{~h})$, i.e., the trails were extracted from the substrate immediately after deposition, and "aged" trails ( $24 \mathrm{~h}, 48 \mathrm{~h})$, i.e., the trails were extracted from the substrate $24 \mathrm{~h}$ and $48 \mathrm{~h}$ after deposition. During these time intervals ( $24 \mathrm{~h}, 48 \mathrm{~h}$ ), the trails were kept at room temperature and approximately 30.5 to $35.2 \% \mathrm{RH}$. In addition to the question of whether the chemical composition of trails changes over time past deposition, we also investigated whether the in- and exclusion of microbes affect the chemical trail composition. For GC-MS analyses, we, therefore, prepared (1) hexane extracts, which were sterile-filtered, and (2) non-sterile-filtered extracts. For trail-following bioassays with $H$. sylvanidis females and microscopic imaging of larval trails, we prepared nonsterile-filtered larval extracts (3).

For the preparation of stock solutions, the number of T. confusum larvae extracted varied according to their availability. However, we extracted a pool of larvae with always a defined number of individuals per microliter. This allowed us to calculate the exact number of LE per microliter finally deposited per trail. For all extracts (stock solutions), larvae were first killed by freezing them at $-20{ }^{\circ} \mathrm{C}$ for up to $30 \mathrm{~min}$ and then thawed for ca. $2 \mathrm{~min}$ at ambient temperature. Thereafter, larvae were extracted by gentle shaking them for $10 \mathrm{~min}$ in $n$-hexane (analytical purification $>98 \%$, VWR, Radnor, USA). By this procedure, the layer of superficial CHCs is removed from larval integuments and dissolved in hexane (Fürstenau and Hilker 2017). The supernatant was further processed. The detailed protocols for the preparation of the above-mentioned three types of extracts are provided below. All samples prepared for GC-MS analysis, bioassays, or microscopic imaging were stored at $-20{ }^{\circ} \mathrm{C}$ prior to usage.

(1) Sterile T. confusum hexane extracts for chemical analysis. The preparation of these extracts aimed to exclude any possible effects of microorganisms originating from the host (e.g., microbes on the cuticle of $T$. confusum larvae), the host habitat (here: wheat grist), or the environment (e.g., airborne microorganisms) on the CHC composition of host trails after different time intervals.

In total, five stock solutions were prepared. The supernatant was removed from the stock solution with a disposable syringe and loaded onto a sterile PVDF filter $(0.22 \mu \mathrm{M}$, Carl Roth, Karlsruhe, Germany), which had been pre-conditioned by rinsing it with $10 \mathrm{ml} n$-hexane. Syringes were cleaned three times with $n$-hexane before being used. The PVDF filter loaded with larval extract was eluted with $n$-hexane. Sterile-filtered extracts were then concentrated to dryness under a gentle stream of nitrogen, dissolved in $n$-hexane, and frozen at $-20^{\circ} \mathrm{C}$ until further processing.

Under a clean bench, a trail of the sterile-filtered hexane extract was applied to the periphery of the bottom part of a glass Petri dish (diameter: $90 \mathrm{~mm}$ ). The dish had previously been cleaned with demineralized water and 70\% ethanol solution (analytical purification $>96.0 \%$, Berkel AHK, Ludwigshafen, Germany) and subsequently sterilized at $175^{\circ} \mathrm{C}$ for $3.5 \mathrm{~h}$. After trail application, the solvent was allowed to evaporate for $1 \mathrm{~min}$. We prepared five replicates (Petri dishes, $N=5$ ) for each investigated time interval past trail deposition. For the $0 \mathrm{~h}$ interval, trails were re-extracted in $n$-hexane immediately after deposition, transferred to a $2 \mathrm{ml}$ vial, evaporated to dryness under a gentle stream of nitrogen, and then dissolved in a distinct volume of $n$-hexane with 1-eicosene as an internal standard (IS, Sigma-Aldrich, Taufkirchen, Germany). For trails to be investigated $24 \mathrm{~h}$ and $48 \mathrm{~h}$ after trail deposition, the dishes were sealed with Parafilm ${ }^{\circledR}$ and kept in a closed sterile box outside the sterile bench. After $24 \mathrm{~h}$ and $48 \mathrm{~h}$ storage, trails were removed from the dishes as described for the immediately analyzed trails.

(2) Non-sterile T. confusum hexane extracts for chemical analysis. To imply possible effects of host-associated or environmentally present microorganisms on the $\mathrm{CHC}$ composition of host trails at different time intervals past trail deposition, larval hexane extracts were prepared under non-sterile conditions.

In total, we prepared six stock solutions. In contrast to the sterile-filtered extracts, here the supernatants were not filtered but directly concentrated to dryness under a gentle 
stream of nitrogen, dissolved in $n$-hexane, and frozen at $-20{ }^{\circ} \mathrm{C}$ for further analysis.

As described for the sterile extracts, trails were deposited on eighteen Petri dishes ( $N=6$ per time interval) which had been cleaned but not sterilized by heat prior to application. After solvent evaporation, Petri dishes were kept open under a laboratory hood for $0 \mathrm{~h}, 24 \mathrm{~h}$, or $48 \mathrm{~h}$ (non-sterile conditions). After the respective time intervals, larval trails were re-extracted in $n$-hexane and quickly transferred to a vial. These extracts were then concentrated under a gentle stream of nitrogen to dryness, and re-dissolved in a distinct volume of $n$-hexane containing again 1-eicosene as internal standard.

(3) Non-sterile T. confusum hexane extracts for bioassays and microscopic imaging. We studied the parasitoid's behavioral responses to larval trails in dependence (a) of the time intervals past deposition ("untreated trails") and (b) of re-dissolving "aged" trails by $n$-hexane ("redissolved trails") (see below for bioassay method). For each type of trail, we prepared seven non-sterile-filtered stock solutions $(N=7)$.

For cryo-SEM (see below), we took the same samples from the stock solutions of larval extracts.

\section{GC-MS Analysis of Sterile- and Non-sterile-Filtered $T$. confusum Host Larval Trails}

Samples were analyzed on a 6890 N GC coupled to a 5975 B VL MS quadrupole mass spectrometer (Agilent Technologies, Waldbronn, Germany). As carrier gas, we used helium with a flow rate of $1.1 \mathrm{ml} \mathrm{min}^{-1}$ and a fused silica column (HP-5MS capillary column, $30 \mathrm{~m} \times 0.25 \mathrm{~mm} \times 0.5 \mu \mathrm{m}$, Agilent Technology, Waldbronn, Germany) as a stationary phase. One $\mu \mathrm{l}$ of each sample was injected at $250{ }^{\circ} \mathrm{C}$ in splitless mode. The oven temperature program started at $40{ }^{\circ} \mathrm{C}$ for $4 \mathrm{~min}$, then raised by $10{ }^{\circ} \mathrm{C} \mathrm{min}{ }^{-1}$ up to $300{ }^{\circ} \mathrm{C}$, which was held for $10^{\circ} \mathrm{min}$. After a solvent delay of $5 \mathrm{~min}$, the detector scanned 4.45 times $\mathrm{s}^{-1}$ for fragments in a range from 35 to $500 \mathrm{~m} / z$ (electron impact [EI] ionization $=70^{\circ} \mathrm{eV}$ ).

Linear alkanes were identified by comparing their retention indices (RIs) and mass spectra with those of an authentic $n$-alkane standard ( $n$-C7 - $n$-C40, Sigma Aldrich, Taufkirchen, Germany). Since no reference standards of methyl-branched alkanes were available to us, we tentatively identified the detected ones based on their characteristic mass spectrometric fragmentation pattern and RIs calculated according to Van den Dool and Kratz (1963). Additionally, RIs and fragmentation pattern of these substances were compared to those published by Fürstenau and Hilker (2017). Individual compounds (linear and methyl-branched alkanes) were quantified relative to the peak area of the IS (1-eicosene).

\section{Trail-Following Bioassays}

To analyze the trail-following responses of $H$. sylvanidis females to $T$. confusum larval trails, we used a "walking arena", i.e. the lower part of a glass Petri dish (diameter $=190 \mathrm{~mm}$ ). We modified the experimental set-up described by Fürstenau and Hilker (2017) as follows. The rim of each Petri dish was coated with an aqueous solution of Teflon (Sigma Aldrich, Taufkirchen, Germany) to prevent parasitoids from climbing up during the bioassays. Below the bottom of the dish, we attached a drawing of two circles (diameter: $80 \mathrm{~mm}$ each) as a template for the trails (one test and one control trail) to be laid on the glass side. A test trail consisted of a hexane extract of $T$. confusum larvae, while a control trail consisted of only hexane. The two circles were $30 \mathrm{~mm}$ apart from each other, and they were about $3 \mathrm{~mm}$ wide on the periphery. Additionally, each circle was divided into eight equally sized sections (length: $31 \mathrm{~mm}$ each). A strip of light-emitting diodes $(\lambda=625 \mathrm{~nm}$, Barthelme $\mathrm{GmbH}$ $\&$ Co, Nuremberg, Germany) was located $300 \mathrm{~mm}$ above the arena for consistent illumination.

We tested the trail-following responses of $H$. sylvanidis females to two different types of larval trails: (1) larval trails at different time intervals after deposition $(0 \mathrm{~h}, 24 \mathrm{~h}$, and $48 \mathrm{~h}$ ); ("untreated trails"); and (2) larval trails at different time intervals after deposition $(0 \mathrm{~h}$ and $48 \mathrm{~h})$; these trails had been treated with $n$-hexane just prior to exposure to the parasitoids ("re-dissolved trails"). All bioassays were performed at room temperature and approximately 35 to $40 \%$ RH on three consecutive days.

When testing untreated trails, we deposited $25 \mu \mathrm{l}$ (corresponding to $5 \mathrm{LE}$ ) of a stock solution on a test circle in the Petri dish. We knew from our previous study that $\mathrm{H}$. sylvanidis shows trail-following behavior already to very lowconcentrated larval extracts (Fürstenau and Hilker 2017). The control trail consisted of $25 \mu \mathrm{l} n$-hexane. Each stock solution was used once for each time interval and type of trail $(N=7)$. Host larval trails tested at later time intervals after deposition were kept under a laboratory hood in open Petri dishes for $24 \mathrm{~h}$ or $48 \mathrm{~h}$ prior to the beginning of the respective bioassays. A bioassay started after releasing one $H$. sylvanidis female at a randomly selected position between the circular control and test trail and lasted $300 \mathrm{~s}$.

Since the results of the bioassay with "untreated trails" revealed that differences in the parasitoid's response were the greatest between $0 \mathrm{~h}$ and $48 \mathrm{~h}$ after trail deposition, we decided to use only these two time intervals in the bioassay with "re-dissolved trails".

When testing the "re-dissolved trails", test and control trails were first applied to the dishes as described for 
"untreated trails". Thereafter, just prior to testing, $25 \mu 1$ additional $n$-hexane was applied on the circular test and the control trail. The hexane was allowed to evaporate for $1 \mathrm{~min}$. The bioassay started then by releasing one $H$. sylvanidis female into the walking arena as described above.

When parasitoid females exhibited trail-following behavior, they intensely antennated host larval trails and followed them in a zigzag line (Howard and Flinn 1990). Holepyris sylvanidis females also tended to reverse the walking direction or to stop following a trail to explore the local area before returning to the trail. Therefore, we evaluated the behavioral response of $H$. sylvanidis to each treatment based on two parameters: (1) the distance covered by a parasitoid was quantified by the number of sections, which a parasitoid fully walked on test and control circles; (2) the total time spent by a parasitoid on each trail was recorded using the computer software "The Observer 3.0" (Noldus Information Technology, Wageningen, The Netherlands). After each run, we replaced the tested individual and changed the position of control and test circle to avoid any biased results due to possible side preferences. After having tested four parasitoids, the bioassay arena was replaced by a new one. When freshly applied trails $(=0 \mathrm{~h})$ were tested, we reused the test arena after cleaning it with demineralized water and a $70 \%$-ethanol solution. Parasitoids, which rested more than $50 \%$ of the observation time, were excluded from the statistical analysis and replaced by a new one. This was the case in less than $4 \%$ (5 occasions) of all experiments. In total, we tested each type of trail at each time interval past deposition with 28 female $H$. sylvanidis $(N=28)$.

\section{Cryo-SEM}

To study possible changes in physical structure of CHCconsisting trails at different time intervals past trail deposition, the cryo-SEM SUPRA 40VP-31-79 (Carl Zeiss SMT Ltd., Oberkochen, Germany) equipped with an EMITECH K250X cryo-preparation unit (Quorum Technologies Ltd., Ashford, Kent, UK) was used.

Hexane extracts of host larvae were applied onto either a polar substrate or a non-polar one. We used the polar substrate because (i) we here always applied host larval trails on glass (polar) when studying the parasitoids' behavioral response to them and (ii) T. confusum might encounter polar substrates in nature (e.g., fine flour with its carbohydrates). We used also an apolar substrate because these substrates might also be present in the natural habitat of $T$. confusum larvae (e.g., waxy seed coats). The polar substrate consisted of $5 \times 5 \mathrm{~mm}$ pieces of ultra-flat silicon wafer thermically covered with a $200 \mathrm{~nm}$ thick, polished $\mathrm{SiO}_{2}$ film (surface roughness: 2-3 ^) (Plano GmbH, Wetzlar, Germany). The substrate had been cleaned prior to use by successive immersions in Piranha solution (mixture of sulphuric acid
$\mathrm{H}_{2} \mathrm{SO}_{4}$ and hydrogen peroxide $\mathrm{H}_{2} \mathrm{O}_{2}, 3: 1$ ), rinsed with distilled water, and dried by compressed air. To obtain apolar substrates, which are known to promote wax crystallization (e.g., Niemietz et al. 2009), we silanized the polar substrate with $1 \mathrm{H}, 1 \mathrm{H}, 2 \mathrm{H}, 2 \mathrm{H}$ perfluorodecyltrichlorosilane $\left(\mathrm{C}_{10} \mathrm{H}_{4} \mathrm{Cl}_{3} \mathrm{~F}_{17} \mathrm{Si}, 97 \%\right.$, SIH5841.0, ABCR GmbH \& Co. KG, Karlsruhe, Germany).

The CHC larval extract was slowly applied in $5 \mu \mathrm{l}$ steps onto the substrate. In total, $25 \mu \mathrm{l}$ could be placed onto the small piece of substrate. The extracts were kept for $1 \mathrm{~h}$ or $48 \mathrm{~h}$ on the substrates at ambient temperature and $25.7 \pm 2.79 \% \mathrm{RH}$ until further processing ("untreated trails"). In addition, we applied a droplet of hexane to samples with larval extracts, which had been on the substrate for $1 \mathrm{~h}$ or $48 \mathrm{~h}$ ("re-dissolved trails").

For cryo-SEM analysis, the substrates were mounted on metal stubs using polyvinyl alcohol (Tissue-Tek, OCT, Sakura Finetek Europe BV, Alphen aan den Rijn, the Netherlands). The solvent was evaporated for at least $1 \mathrm{~h}$ to avoid interferences inside the cryo-SEM. Subsequently, the samples were shock-frozen in liquid nitrogen in the slushing chamber, transferred to the cryo-preparation chamber at $-140{ }^{\circ} \mathrm{C}$, sublimed for $15 \mathrm{~min}$ at $-70{ }^{\circ} \mathrm{C}$, sputter-coated with platinum (layer thickness ca. $10 \mathrm{~nm}$ ), transferred to the SEM, and then examined in a frozen state at $5 \mathrm{kV}$ accelerating voltage and $-100{ }^{\circ} \mathrm{C}$ temperature. Cryo-SEM micrographs were taken using the software Smart SEM 05.03.05 (Carl Zeiss SMT Ltd., Oberkochen, Germany).

\section{Statistical Analysis}

We conducted all statistical analysis using $\mathrm{R}$, version 4.0.2 ( $\mathrm{R}$ Core Team 2020), except for the analysis of similarity percentages (SIMPER), which was performed in "PAST", version 3.26 (Hammer et al. 2001).

For statistical comparison of the quantitative chemical pattern of sterile- or non-sterile-filtered trails, we selected the analyzed compounds by the following criteria: (i) presence in more than $50 \%$ of all samples taken per time interval past deposition; (ii) peak area larger than $0.01 \%$ of the total peak area. If a compound was meeting criterion (i), but not criterion (ii) (i.e., the compound was below the detection limit), the "in some samples, missing value" was handled as follows. We used the "rnorm()"-function in R to generate a random peak for each missing value. We selected the smallest peak area, which the missing value had in other samples of the same time interval and trail type (sterile- or non-sterile-filtered), as mean and calculated the standard deviation based on the three smallest peak areas. To avoid any bias in the subsequent statistical analyses, nine pseudo-peaks were generated in the samples of sterile-filtered larval trails, while one pseudo-peak was used for non-sterile-filtered larval trails. We normalized the peak areas of selected compounds 
by referring the quantity (peak area) of each compound to the IS and then to one larval equivalent (LE).

To assess whether the chemical composition of sterilefiltered larval CHC trails varied quantitatively over time, quantities of each selected compound were compared by a one-way ANOVA when data were normally distributed. If the Shapiro-Wilk test of normality revealed that data of some compounds were not normally distributed at all time intervals, the Kruskal-Wallis test was computed instead, followed by Wilcoxon's rank-sum test with Bonferroni-Holm correction. Furthermore, the dissimilarity in the chemical composition of these larval trails was tested by running a one-way analysis of similarity (ANOSIM). For this purpose, we calculated the relative amounts of detected compounds in one LE per time interval and summed them up to $100 \%$. Based on Bray-Curtis dissimilarity, an ANOSIM was performed with 99,999 random permutations using the package "vegan" (version 2.5-6, Oksanen et al. 2019) in R. The dissimilarity of groups is stated by the $R$-value; groups with an $R$-value close to 0 are highly similar, while groups with an $R$-value close to 1 can be clearly discriminated (Clarke 1993). For visualization of results obtained by the ANOSIM, a non-metric multidimensional scaling (NMDS) was calculated based on the Bray-Curtis dissimilarity. To evaluate how well the algorithm of NMDS fits in the used data set, we calculated the associated stress value. According to Dexter et al. (2018), a stress value $<0.1$ indicates that the applied NMDS is a good representative. A SIMPER was implemented to identify compounds that contributed the most to the dissimilarity. Likewise, the statistical analysis of trails from non-sterile-filtered larval extracts was performed.

For each time interval, the quantitative chemical compositions of sterile- and non-sterile-filtered larval $\mathrm{CHC}$ trails were statistically analyzed by using a Student's $t$ - test for independent data. When the variance was unequal in both data sets, a Welch's $t$-test was applied instead. If data of one $\mathrm{CHC}$ trail type were not normally distributed according to the Shapiro-Wilk test of normality, we used Wilcoxon's ranksum test for independent data.

The behavioral responses of $H$. sylvanidis to host larval trails were statistically analyzed (a) by comparing the walking distances and residence times on test circles with the $\mathrm{CHC}$ trail and on control circles with the solvent. These parameters were statistically compared by a Student's $t$ - test for paired samples. If data sets were not normally distributed according to the Shapiro-Wilk test, we performed a Wilcoxon's signed-rank test for paired data. Furthermore, we compared (b) whether walking distances and residence times on test circles differed when trails were offered $0 \mathrm{~h}$, $24 \mathrm{~h}$, or $48 \mathrm{~h}$ after deposition. Therefore, we determined the difference $(\Delta)$ in walking distance and residence time spent on the test and the control circle for each time interval. When analyzing the responses to "untreated test and control trails", the differences in residence times and walking distances in bioassays with trails tested $0 \mathrm{~h}, 24 \mathrm{~h}$, or $48 \mathrm{~h}$ after deposition were not normally distributed according to the Shapiro-Wilk test. Therefore, we performed a KruskalWallis test for each parameter (walking distance, residence time) followed by a pairwise Wilcoxon's rank-sum test with Bonferroni-Holm correction. When comparing the responses to "re-dissolved trails" on test circles $0 \mathrm{~h}$ and $48 \mathrm{~h}$ after deposition, we applied a Student's $t$ - test for each parameter (walking distance, residence time) if the data were normally distributed. If normal distribution of data was absent, a Wilcoxon's rank-sum test was performed.

\section{Results}

\section{No Changes in the Chemical Composition of $T$. confusum Host Larval Trails in the Course of Time}

We addressed the question of whether host larval trails, which had been excluded from microbial degradation, changed their chemical composition in the course of time $(0 \mathrm{~h}, 24 \mathrm{~h}$, and $48 \mathrm{~h}$ ) past deposition. Our chemical analysis revealed the same 20 compounds in all investigated sterilefiltered trails, regardless of the time past trail deposition (Table 1).

The detected trail compounds included six $n$-alkanes, twelve monomethyl-branched alkanes, and two dimethylbranched alkanes with a chain length from $\mathrm{C} 25$ to $\mathrm{C} 31$. In all CHC profiles of larval trails and at all time intervals past trail deposition $n$-alkanes were the dominating substance group accounting for $80 \%$, while methyl-branched alkanes accounted for about $20 \%$ (Table 1). The quantities of individual CHCs did not differ significantly between freshly laid trails $(0 \mathrm{~h}), 24 \mathrm{~h}$ - and $48 \mathrm{~h}$-old ones. Additionally, the ANOSIM confirmed that the CHC compositions of larval trails were highly similar at all time intervals past trail deposition $(R=-0.141, P=0.941)$. CHC profiles of these trails clustered closely in a NMDS plot calculated on the relative proportions of single compounds within one LE of $T$. confusum (Fig. 1a). According to the SIMPER analysis, $n$-C25, $n$-C27, and $n$-C29 (entries 1, 8, and 18, Table 1) contributed the most to the moderate dissimilarity (59\%, Table S1). Hence, at sterile conditions, CHC profiles of freshly laid host larval trails and those, which were $24 \mathrm{~h}$ or $48 \mathrm{~h}$ old, did not significantly differ. The $\mathrm{CHC}$ profiles did not change within two days.

We further addressed the question of whether $\mathrm{CHC}$ profiles of host larval trails kept under non-sterile conditions change over time. The detected compounds of non-sterile trails after the different time intervals past deposition (Fig. 2) included linear alkanes, which accounted for almost $70 \%$ in $\mathrm{CHC}$ profiles of these trails, and methyl-branched alkanes, 
Table 1 Cuticular hydrocarbons identified from sterile-filtered hexane extracts Of Tribolium confusum larvae 0 H, 24 H OR 48 H after trail (extract) deposition. Mean amounts $\left(\mathrm{NG} \pm \mathrm{SE} \mathrm{LE}^{-1}\right)$ And Relative Quantities (\% PER LE) are given

\begin{tabular}{|c|c|c|c|c|c|c|c|c|c|c|c|}
\hline \multirow[b]{3}{*}{ No. $^{a}$} & \multirow[b]{3}{*}{ Compound $^{\mathrm{b}}$} & \multirow[b]{3}{*}{$\mathrm{ID}^{\mathrm{c}}$} & \multirow[b]{3}{*}{$\mathrm{RI}_{\mathrm{cal}}^{\mathrm{d}}$} & \multirow[b]{3}{*}{$\mathrm{RI}_{\mathrm{lit}}^{\mathrm{e}}$} & \multicolumn{7}{|c|}{ Hours after trail deposition ${ }^{\mathrm{f}}$} \\
\hline & & & & & \multicolumn{2}{|c|}{0} & \multicolumn{2}{|l|}{24} & \multicolumn{2}{|l|}{48} & \multirow[b]{2}{*}{$P^{\mathrm{h}}$} \\
\hline & & & & & $\overline{\text { Mean } \pm S E ~(n g)^{g}}$ & $(\%)^{\mathrm{g}}$ & Mean \pm SE $(n g)^{g}$ & $(\%)^{g}$ & Mean \pm SE $(n g)^{g}$ & $(\%)^{\mathrm{g}}$ & \\
\hline 1 & $n-\mathrm{C} 25$ & I & 2498 & 2500 & $20.52 \pm 3.04$ & 17.22 & $17.99 \pm 3.53$ & 17.14 & $21.83 \pm 2.40$ & 17.63 & ns \\
\hline 2 & $11-/ 13-\mathrm{MeC} 25$ & II & 2533 & 2534 & $0.13 \pm 0.03$ & 0.11 & $0.13 \pm 0.03$ & 0.12 & $0.15 \pm 0.03$ & 0.12 & $\mathrm{~ns}$ \\
\hline 3 & $5-\mathrm{MeC} 25$ & III & 2550 & 2550 & $0.08 \pm 0.02$ & 0.07 & $0.08 \pm 0.02$ & 0.07 & $0.10 \pm 0.01$ & 0.08 & ns \\
\hline 4 & 3-MeC25 & IV & 2573 & 2571 & $0.40 \pm 0.09$ & 0.33 & $0.36 \pm 0.10$ & 0.33 & $0.40 \pm 0.08$ & 0.32 & ns \\
\hline 5 & $n-\mathrm{C} 26$ & $\mathrm{~V}$ & 2598 & 2599 & $3.10 \pm 0.43$ & 2.58 & $2.61 \pm 0.54$ & 2.45 & $3.07 \pm 0.34$ & 2.48 & $\mathrm{~ns}$ \\
\hline 6 & $10-/ 11-/ 12-/ 13-\mathrm{MeC} 26$ & VI & 2633 & 2632 & $0.53 \pm 0.04$ & 0.46 & $0.46 \pm 0.11$ & 0.43 & $0.51 \pm 0.09$ & 0.41 & ns \\
\hline 7 & 4-MeC26 & VII & 2656 & 2656 & $0.27 \pm 0.03$ & 0.23 & $0.21 \pm 0.06$ & 0.21 & $0.22 \pm 0.05$ & 0.18 & ns \\
\hline 8 & $n-\mathrm{C} 27$ & VIII & 2700 & 2700 & $53.27 \pm 5.70$ & 45.07 & $46.66 \pm 7.15$ & 45.49 & $57.52 \pm 5.41$ & 46.65 & ns \\
\hline 9 & $11-/ 13-\mathrm{MeC} 27$ & IX & 2730 & 2731 & $8.10 \pm 0.75$ & 6.95 & $7.25 \pm 1.51$ & 6.91 & $8.61 \pm 1.12$ & 6.91 & $\mathrm{~ns}$ \\
\hline 10 & 5-MeC27 & $\mathrm{X}$ & 2747 & 2750 & $3.81 \pm 0.32$ & 3.28 & $3.35 \pm 0.65$ & 3.25 & $3.84 \pm 0.45$ & 3.11 & $\mathrm{~ns}$ \\
\hline 11 & 3-MeC27 & XI & 2771 & 2773 & $3.50 \pm 0.39$ & 2.97 & $3.07 \pm 0.59$ & 2.94 & $3.58 \pm 0.38$ & 2.89 & $\mathrm{~ns}$ \\
\hline 12 & 5,X-DiMeC27 & XII & 2778 & 2781 & $1.95 \pm 0.15$ & 1.69 & $1.71 \pm 0.37$ & 1.64 & $1.86 \pm 0.27$ & 1.50 & $\mathrm{~ns}$ \\
\hline 13 & $n-\mathrm{C} 28$ & XIII & 2797 & 2799 & $4.86 \pm 0.53$ & 4.11 & $4.23 \pm 0.71$ & 4.11 & $4.97 \pm 0.50$ & 4.03 & $\mathrm{~ns}$ \\
\hline 14 & 3,X-DiMeC27 & XIV & 2803 & 2807 & $2.64 \pm 0.18$ & 2.28 & $2.15 \pm 0.49$ & 2.04 & $2.42 \pm 0.31$ & 1.97 & $\mathrm{~ns}$ \\
\hline 15 & $12-/ 13-/ 14-\mathrm{MeC} 28$ & XV & 2828 & 2831 & $0.93 \pm 0.07$ & 0.81 & $1.07 \pm 0.32$ & 1.02 & $0.70 \pm 0.14$ & 0.56 & $\mathrm{~ns}$ \\
\hline 16 & 4-MeC28 & XVI & 2854 & 2856 & $0.54 \pm 0.03$ & 0.47 & $0.47 \pm 0.13$ & 0.46 & $0.36 \pm 0.07$ & 0.30 & $\mathrm{~ns}$ \\
\hline 17 & $n-\mathrm{C} 29$ & XVIII & 2897 & 2904 & $11.77 \pm 1.28$ & 9.99 & $10.42 \pm 1.86$ & 10.04 & $11.96 \pm 1.20$ & 9.71 & $\mathrm{~ns}$ \\
\hline 18 & $11-/ 13-\mathrm{MeC} 29$ & XIX & 2928 & 2931 & $1.25 \pm 0.12$ & 1.07 & $1.15 \pm 0.29$ & 1.06 & $0.93 \pm 0.09$ & 0.78 & $\mathrm{~ns}$ \\
\hline 19 & 3-МeC29 & XXI & 2970 & 2978 & $0.23 \pm 0.05$ & 0.20 & $0.27 \pm 0.11$ & 0.22 & $0.31 \pm 0.06$ & 0.27 & $\mathrm{~ns}$ \\
\hline 20 & $n$-C31 & XXV & 3096 & 3100 & $0.13 \pm 0.01$ & 0.12 & $0.08 \pm 0.04$ & 0.07 & $0.10 \pm 0.01$ & 0.08 & $\mathrm{~ns}$ \\
\hline
\end{tabular}

${ }^{a}$ Number of peaks identified in the total ion chromatogram

${ }^{\mathrm{b}} n$-alkanes were identified by comparing RIs and mass spectra with authentic standards. Methyl-branched alkanes were tentatively identified by the diagnostic ions, which resulted from favored fragmentation at branched points (see by Fürstenau and Hilker 2017, and by comparing RIs with data from literature

${ }^{c}$ Identity of CHCs used for comparison of sterile- and non-sterile-filtered larval host trails

${ }^{\mathrm{d}} \mathrm{RI}_{\text {cal }}=$ Retention index calculated on a HP-5 ms capillary column $(30 \mathrm{~m} \times 0.25 \mathrm{~mm} \times 0.5 \mu \mathrm{m})$

${ }^{\mathrm{e}} \mathrm{RI}_{\text {lit }}=$ Retention index as reported for compounds analyzed on HP-5 ms or similar columns in the database (http://www.pherobase.com/) and by Fürstenau and Hilker (2017)

${ }^{\mathrm{f}}$ For the preparation of host larval trails, see experimental part

${ }^{\mathrm{g}}$ For each time interval, five replicates were used $(N=5)$

${ }^{\text {h}}$ For each compound, a $p$ value denotes a significant quantitative difference between sterile-filtered larval CHC trails of $T$. confusum $0 \mathrm{~h}, 24 \mathrm{~h}$, and $48 \mathrm{~h}$ after trail deposition (one-way ANOVA or Kruskal-Wallis test, ns = not significant)

which made up about $30 \%$ of the detected CHCs (Table 2). No significant differences were measured between the relative quantity of individual compounds present in freshly laid trails $(0 \mathrm{~h})$ and in "aged trails" $24 \mathrm{~h}$ and $48 \mathrm{~h}$ after deposition. As a result, the CHC profiles clustered closely in a NMDS plot (Fig. 1b). This finding indicated a strong similarity of the chemical composition of non-sterile-filtered larval trails analyzed after different times past deposition. This similarity was confirmed by the results of the ANOSIM $(R=-0.144, P=0.953)$. The SIMPER analysis revealed that $n$-C25, $n$-C27, 11-/13-MeC27, and 5-MeC27 (entries 1, 8, 9 , and 10) contributed the most to the moderate dissimilarity (57\%, Table S2). Thus, at non-sterile conditions, no significant differences were detected in the qualitative and quantitative $\mathrm{CHC}$ pattern of $0 \mathrm{~h}-, 24 \mathrm{~h}$ - and $48 \mathrm{~h}$-old trails of $T$. confusum larvae. The long-chain $\mathrm{CHC}$ profiles were stable over a period of two days.

When comparing the chemical composition of sterileand non-sterile-filtered trails for each time interval past trail deposition, we found that sterile-filtered trails were missing five compounds, which were detected in the non-sterilefiltered trails (ID XVII, XX, XXII, XXIII, and XXIV in Table 2). When statistically comparing the quantities of the compounds present in both $\mathrm{CHC}$ trail types, we found that at all time intervals the quantity of individual CHCs was significantly higher in non-sterile-filtered trails than in sterile 


\section{$\oplus 0 \mathrm{~h} \quad \mathrm{O} 24 \mathrm{~h} \quad \nabla 48 \mathrm{~h}$}

\section{a) sterile-filtered larval extracts}

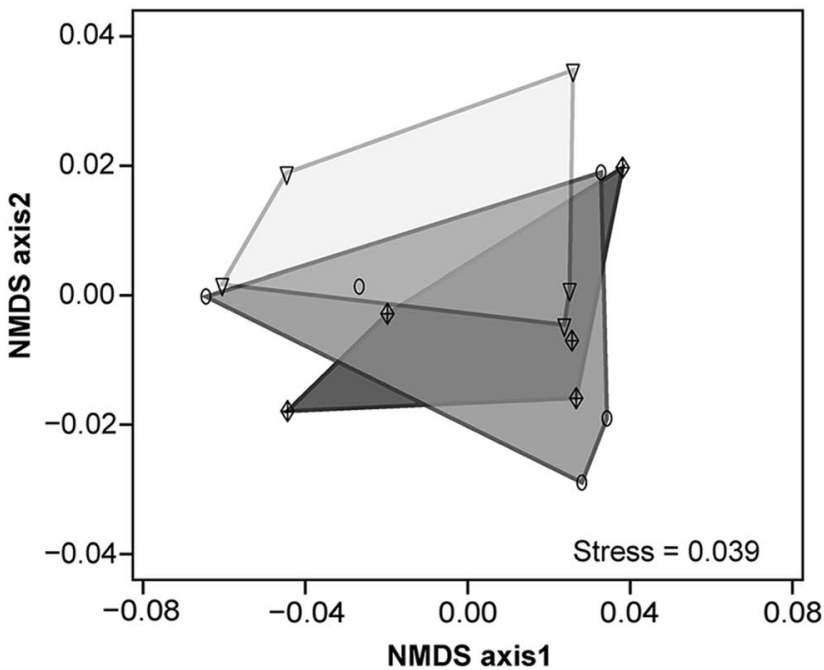

Fig. 1 Non-metric multidimensional scaling (NMDS) visualization of the CHC composition of trails consisting of two differently treated Tribolium confusum larval extracts $0 \mathrm{~h}, 24 \mathrm{~h}$, and $48 \mathrm{~h}$ after trail deposition: a) sterile-filtered hexane extracts, which were applied

ones (for $p$-values see Table S3). Only the quantities of $n$ $\mathrm{C} 25$ and $n$-C27 (ID I and VIII in Table S3) did not significantly differ between both $\mathrm{CHC}$ trail types at the respective time intervals.

\section{Change of Kairomonal Activity of Host Trails in the Course of Time}

Our bioassays confirmed previous results of Fürstenau and Hilker (2017) and show a clear kairomonal activity of freshly laid CHC trails, but a decrease of the kairomonal effect within two days after trail deposition. Parasitoid females covered a significantly greater distance on freshly laid CHC trails than on "aged" $24 \mathrm{~h}$ - or $48 \mathrm{~h}$-old ones (Fig. 3a). When comparing the walking distance on CHCconsisting test trails and (hexane) control trails, significantly greater distances were covered on $\mathrm{CHC}$ trails $0 \mathrm{~h}$ and $24 \mathrm{~h}$ after trail deposition, while this preference was lost $48 \mathrm{~h}$ after trail deposition (Table S4). When comparing the residence time on test and control trails, the residence time on test trails was always significantly higher than on control trails (Table S4). However, the time spent by the parasitoids on test trails decreased considerably with the "age" of a trail. Parasitoids spent significantly more time on freshly laid CHC trails than on $24 \mathrm{~h}$ - or 48 h-old ones (Fig. 3b).

We further studied whether the kairomonal effect of $48 \mathrm{~h}$-old larval trails could be reactivated by applying b) non-sterile-filtered larval extracts

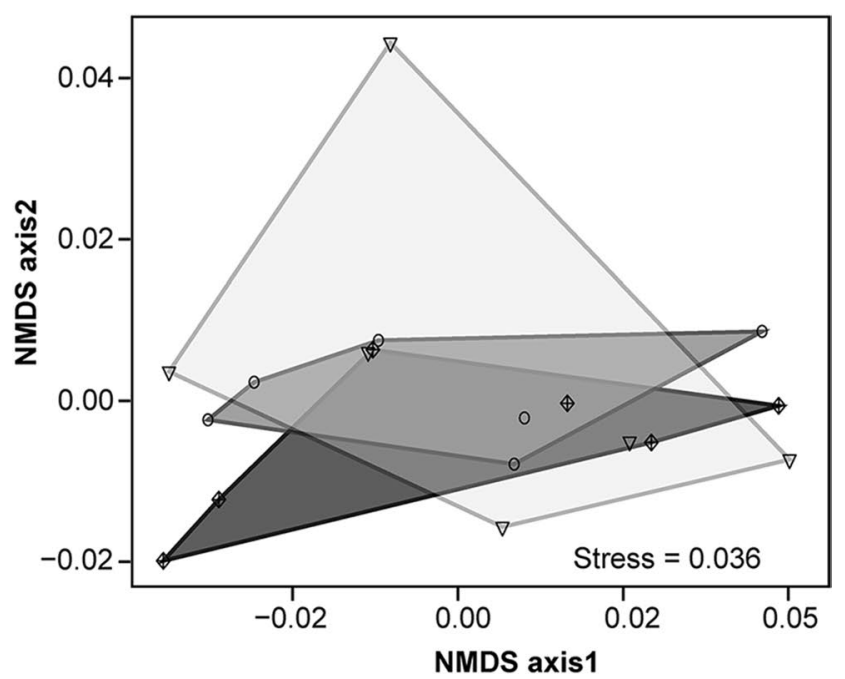

and kept under sterile conditions $(N=5)$ and b) non-sterile-filtered hexane extracts, which were applied and kept under non-sterile conditions $(N=6)$

hexane to them. Parasitoids covered a similar walking distance and spent similar time on $48 \mathrm{~h}$-old CHC trails with hexane reapplication as on freshly laid $(0 \mathrm{~h})$, untreated CHC trails (Fig. 4a, b). When comparing the parasitoid's response to $48 \mathrm{~h}$-old $\mathrm{CHC}$ trails with hexane reapplication to the hexane control trails, the results show that they covered a greater distance on re-dissolved $48 \mathrm{~h}$-old test trails than on the controls and spent significantly more time on these trails (Table S4). Hence, an application of hexane fully restored the kairomonal activity of $48 \mathrm{~h}$-old CHC trails.

\section{Change of Trail Structures in the Course of Time}

We investigated by cryo-SEM whether trails obtained from hexane extracts of $T$. confusum larvae show changes in physical structures over time past trail deposition.

Both on a polar and non-polar substrate, untreated trails changed their microscopically visible structures within $48 \mathrm{~h}$ (Fig. 5A1-A3, B1-3). One hour after application of the $\mathrm{CHC}$ trail onto the substrate, fluid patches or droplets were visible (Fig. 5A2, B2). On the polar substrate, the larval trail extract formed a ring-shaped pattern, which occurred $1 \mathrm{~h}$ after deposition and evaporation of hexane; such a formation has also been described as "coffee-ring effect" (Deegan et al. 1997, 2000). After 48 h, solidified filamentous structures were visible (Fig. 5A3). The filamentous structures were visible as clearly outlined, 

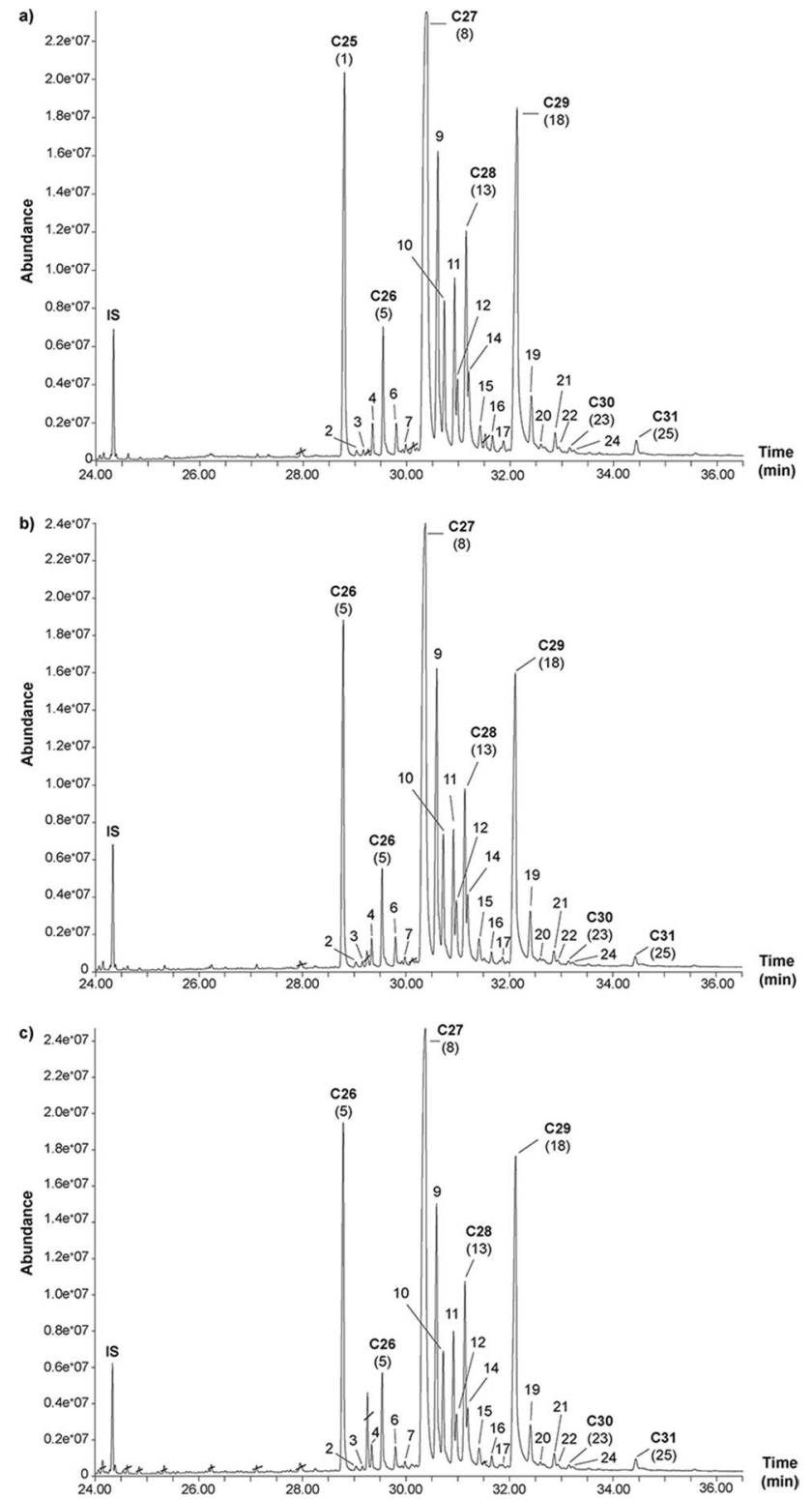

Fig. 2 Partial total ion chromatograms (TIC) of trails consisting of non-sterile-filtered hexane extracts of Tribolium confusum larvae; trails (hexane extracts) were extracted from a substrate and analyzed a) $0 \mathrm{~h}$, b) $24 \mathrm{~h}$, and c) $48 \mathrm{~h}$ after deposition. Numbers above peaks refer to the identified compounds listed in Table 2 . The $n$-alkanes $(n-\mathrm{C} 25-n-\mathrm{C} 31)$ detected in the larval trails are highlighted in bold. Crossed-out compounds are contaminations

elongated threads on the polar substrate, while they were embedded in a solidified, amorphous layer with a gibbous surface on the apolar substrate (Fig. 5B3).

When applying hexane to a $48 \mathrm{~h}$-old $\mathrm{CHC}$ trail, again fluidlike structures of these re-dissolved trails were visible, i.e. a fluid layer with granules on the polar substrate (Fig. 5A4) and droplets on the apolar substrate (Fig. 5B4).

\section{Discussion}

Our present study addressed the question of whether the quick loss of kairomonal activity (within two days) of host larval trails used by a foraging larval parasitoid is due to chemical changes which might be caused by microbial activity. Our GC-MS analyses revealed that the chemical pattern of trails from $T$. confusum larval extracts (hereafter referred to larval trails) does not change over a period of $48 \mathrm{~h}$ after trail deposition, regardless of whether the possible microbial activity was excluded or not. Thus, no hints were detected (i) on chemical degradation of host CHC trails, (ii) on microbial contribution to a change in the chemical composition of the trails, and (iii) on the quantitative loss of CHCs due to e.g., evaporation. Our bioassays showed that the kairomonal activity of non-sterile CHC trails was restored by adding hexane as solvent to an inactive $48 \mathrm{~h}$-old trail. These reactivated larval trails induced a comparable trail-following behavior in $H$. sylvanidis as we could observe with freshly laid trails. Cryo-SEM analysis showed that the $\mathrm{CHC}$ trails formed filamentous structures $48 \mathrm{~h}$ after the trail deposition, which were re-dissolved by hexane and then forming fluidic layers or droplets. Our results suggest that the quick loss of kairomonal activity of host larval trails after a short time is neither due to microbial degradation nor to a chemical change in the $\mathrm{CHC}$ profile, but due to a shift in the physical state and molecular packing of the $\mathrm{CHC}$ blend. The observed gradual assembling of host larval CHCs in filamentous structures after trail deposition might render the $\mathrm{CHCs}$ less accessible to the olfactory receptors by which insects perceive CHCs (Ozaki and Wada-Katsumata 2010). Such a reduced perceptibility is expected to reduce the kairomonal activity of the trails.

The physical states of individual, long-chained CHCs range from liquid to solid at ambient temperature. The CHC profile of $T$. confusum larvae is dominated by linear alkanes with a chain length from $\mathrm{C} 25$ to $\mathrm{C} 31$. These $\mathrm{CHCs}$ are known to form solid structures at ambient temperature and start melting at temperatures above $50{ }^{\circ} \mathrm{C}$ (Gibbs and Pomonis 1995; Maroncelli et al. 1982). Some long-chain monomethyl-branched alkanes can also solidify at room temperature range (Brooks et al. 2015), but the molecular packing and thus the melting behavior of this $\mathrm{CHC}$ type depends particularly on the position of the methyl group (Gibbs 1998). For example, 3-MeC25 becomes liquid at $40{ }^{\circ} \mathrm{C}$, whereas $11-\mathrm{MeC} 25$ does at approx. $20^{\circ} \mathrm{C}$. Dimethyl-branched alkanes show the lowest melting temperatures among all CHC types present on the cuticle of T. confusum larvae and are most likely liquid at room temperature (Gibbs 1998; Gibbs and Pomonis 1995).

The $T$. confusum larval extracts deposited as trails consisted of a blend of different CHC types with different 
Table 2 Cuticular hydrocarbons identified from non-sterile-filtered hexane extracts of Tribolium confusum larvae $0 \mathrm{~h}, 24 \mathrm{~h}$ or $48 \mathrm{~h}$ after trail (extract) deposition. Mean amounts (ng \pm SE LE-1) and relative quantities (\% per LE) are given

\begin{tabular}{|c|c|c|c|c|c|c|c|c|c|c|c|}
\hline \multirow[b]{3}{*}{ No. ${ }^{a}$} & \multirow[b]{3}{*}{ Compound $^{\mathrm{b}}$} & \multirow[b]{3}{*}{$\mathrm{ID}^{\mathrm{c}}$} & \multirow[b]{3}{*}{$\mathrm{RI}_{\text {cal }}{ }^{\mathrm{d}}$} & \multirow[b]{3}{*}{$\mathrm{RI}_{\mathrm{lit}}^{\mathrm{e}}$} & \multicolumn{7}{|c|}{ Hours after trail deposition ${ }^{\mathrm{f}}$} \\
\hline & & & & & \multicolumn{2}{|l|}{0} & \multicolumn{2}{|l|}{24} & \multicolumn{2}{|l|}{48} & \multirow[b]{2}{*}{$P^{\mathrm{g}}$} \\
\hline & & & & & Mean \pm SE (ng) & $(\%)$ & Mean \pm SE (ng) & $(\%)$ & Mean \pm SE (ng) & $(\%)$ & \\
\hline 1 & $n-\mathrm{C} 25$ & I & 2503 & 2500 & $20.12 \pm 0.67$ & 11.26 & $19.47 \pm 0.77$ & 11.41 & $19.10 \pm 0.49$ & 11.25 & ns \\
\hline 2 & $11-/ 13-\mathrm{MeC} 25$ & II & 2534 & 2534 & $0.56 \pm 0.06$ & 0.31 & $0.46 \pm 0.03$ & 0.27 & $0.63 \pm 0.10$ & 0.37 & ns \\
\hline 3 & $5-\mathrm{MeC} 25$ & III & 2550 & 2550 & $0.36 \pm 0.04$ & 0.20 & $0.31 \pm 0.02$ & 0.18 & $0.38 \pm 0.06$ & 0.22 & ns \\
\hline 4 & $3-\mathrm{MeC} 25$ & IV & 2573 & 2571 & $1.31 \pm 0.12$ & 0.73 & $1.22 \pm 0.06$ & 0.71 & $1.28 \pm 0.07$ & 0.75 & ns \\
\hline 5 & $n-\mathrm{C} 26$ & $\mathrm{~V}$ & 2599 & 2599 & $5.19 \pm 0.23$ & 2.90 & $5.02 \pm 0.15$ & 2.95 & $5.12 \pm 0.15$ & 3.01 & ns \\
\hline 6 & $10-/ 11-/ 12-/ 13-\mathrm{MeC} 26$ & VI & 2633 & 2632 & $1.44 \pm 0.16$ & 0.79 & $1.37 \pm 0.09$ & 0.80 & $1.50 \pm 0.15$ & 0.88 & ns \\
\hline 7 & 4-MeC26 & VII & 2658 & 2656 & $0.79 \pm 0.08$ & 0.44 & $0.66 \pm 0.05$ & 0.39 & $0.82 \pm 0.10$ & 0.48 & ns \\
\hline 8 & $n-\mathrm{C} 27$ & VIII & 2708 & 2700 & $56.50 \pm 2.77$ & 31.50 & $53.37 \pm 1.68$ & 31.28 & $52.23 \pm 0.78$ & 30.75 & ns \\
\hline 9 & $11-/ 13-\mathrm{MeC} 27$ & IX & 2735 & 2731 & $15.75 \pm 1.56$ & 8.68 & $15.13 \pm 0.90$ & 8.86 & $14.72 \pm 0.95$ & 8.62 & ns \\
\hline 10 & $5-\mathrm{MeC} 27$ & $\mathrm{X}$ & 2750 & 2750 & $7.61 \pm 0.65$ & 4.20 & $7.24 \pm 0.34$ & 4.24 & $8.30 \pm 1.19$ & 4.85 & ns \\
\hline 11 & 3-MeC27 & XI & 2774 & 2773 & $7.30 \pm 0.30$ & 4.07 & $7.17 \pm 0.10$ & 4.21 & $7.02 \pm 0.16$ & 4.13 & ns \\
\hline 12 & 5,X-DiMeC27 & XII & 2781 & 2781 & $3.79 \pm 0.35$ & 2.09 & $3.47 \pm 0.19$ & 2.03 & $3.36 \pm 0.18$ & 1.97 & ns \\
\hline 13 & $n-\mathrm{C} 28$ & XIII & 2801 & 2799 & $10.45 \pm 0.41$ & 5.84 & $10.28 \pm 0.18$ & 6.03 & $10.18 \pm 0.21$ & 5.99 & ns \\
\hline 14 & 3,X-DiMeC28 & XIV & 2806 & 2807 & $5.10 \pm 0.35$ & 2.83 & $4.82 \pm 0.16$ & 2.82 & $4.80 \pm 0.23$ & 2.82 & ns \\
\hline 15 & $12-/ 13-/ 14-\mathrm{MeC} 28$ & $\mathrm{XV}$ & 2830 & 2831 & $1.98 \pm 0.19$ & 1.09 & $1.86 \pm 0.12$ & 1.09 & $1.87 \pm 0.18$ & 1.09 & ns \\
\hline 16 & 4-MeC28 & XVI & 2856 & 2856 & $1.50 \pm 0.12$ & 0.83 & $1.29 \pm 0.05$ & 0.76 & $1.35 \pm 0.11$ & 0.79 & ns \\
\hline 17 & 3-MeC28 & XVII & 2873 & 2872 & $0.71 \pm 0.16$ & 0.39 & $0.44 \pm 0.02$ & 0.26 & $0.57 \pm 0.08$ & 0.33 & ns \\
\hline 18 & $n-\mathrm{C} 29$ & XVIII & 2904 & 2904 & $29.10 \pm 1.57$ & 16.18 & $28.06 \pm 0.52$ & 16.46 & $27.68 \pm 0.33$ & 16.28 & ns \\
\hline 19 & $11-/ 13-\mathrm{MeC} 29$ & XIX & 2930 & 2931 & $4.51 \pm 0.43$ & 2.49 & $4.06 \pm 0.32$ & 2.38 & $4.10 \pm 0.39$ & 2.40 & ns \\
\hline 20 & 5-MeC29 & $\mathrm{XX}$ & 2948 & 2948 & $0.91 \pm 0.11$ & 0.50 & $0.70 \pm 0.02$ & 0.41 & $0.71 \pm 0.05$ & 0.41 & ns \\
\hline 21 & 3-MeC29 & XXI & 2972 & 2978 & $1.40 \pm 0.10$ & 0.78 & $1.29 \pm 0.05$ & 0.76 & $1.34 \pm 0.09$ & 0.78 & ns \\
\hline 22 & 5,X-DiMeC29 & XXII & 2979 & 2980 & $0.83 \pm 0.05$ & 0.46 & $0.65 \pm 0.03$ & 0.38 & $0.70 \pm 0.06$ & 0.41 & ns \\
\hline 23 & $n-\mathrm{C} 30$ & XXIII & 2999 & 3000 & $0.64 \pm 0.03$ & 0.35 & $0.54 \pm 0.03$ & 0.32 & $0.58 \pm 0.05$ & 0.34 & ns \\
\hline 24 & 3,X-DiMeC29 & XXIV & 3004 & 3005 & $0.68 \pm 0.07$ & 0.38 & $0.55 \pm 0.04$ & 0.32 & $0.61 \pm 0.12$ & 0.36 & $\mathrm{~ns}$ \\
\hline 25 & $n-\mathrm{C} 31$ & XXV & 3098 & 3100 & $1.29 \pm 0.04$ & 0.73 & $1.15 \pm 0.10$ & 0.68 & $1.19 \pm 0.05$ & 0.70 & ns \\
\hline
\end{tabular}

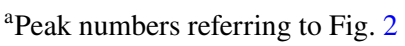

${ }^{\mathrm{b}} n$-alkanes were identified by comparing RIs and mass spectra with authentic standards. Methyl alkanes were tentatively identified by the diagnostic ions, which resulted from favored fragmentation at branched points (see by Fürstenau and Hilker 2017), and by comparing RIs with data from literature

${ }^{\mathrm{C}}$ Identity of CHCs used for comparison of sterile and non-sterile-filtered larval host trails

${ }^{\mathrm{d}} \mathrm{RI}_{\text {cal }}=$ Retention index calculated on a HP-5 ms capillary column $(30 \mathrm{~m} \times 0.25 \mathrm{~mm} \times 0.5 \mu \mathrm{m})$

${ }^{\mathrm{e}} \mathrm{RI}_{\text {lit }}=$ Retention index as reported for compounds analyzed on HP-5 ms or similar columns in the database (http://www.pherobase.com/) and by Fürstenau and Hilker (2017)

${ }^{\mathrm{f}}$ For the preparation of host larval trails, see experimental part

${ }^{\mathrm{g}}$ For each time interval, six replicates were used $(N=6)$

${ }^{\text {h}}$ For each compound, the $p$ value denotes a significant quantitative difference between non-sterile-filtered larval CHC trails of $T$. confusum 0 h, $24 \mathrm{~h}$, and $48 \mathrm{~h}$ after trail deposition (one-way ANOVA or Kruskal-Wallis test, ns = not significant)

physical states at ambient temperature. How might the physical state of this blend change within $48 \mathrm{~h}$ and lose its kairomonal activity?

We suggest the following scenario: After evaporation of the solvent hexane, the CHCs extracted from $T$. confusum host larvae began to rearrange themselves due to intermolecular interactions (e.g., van der Waals forces). These selfassembling processes might result in a more ordered state, and thus a change from liquid to solid occurred. The gradual decrease of the kairomonal activity of the larval trails suggests that the CHCs first formed a solid-liquid matrix in which some components had already solidified, whereas others were still present as liquids and therefore perceivable for $H$. sylvanidis. In the course of time, the $\mathrm{CHC}$ solidification might have gradually proceeded, thus rendering those $\mathrm{CHCs}$ informative to the parasitoid in their liquid phase no longer 
a)

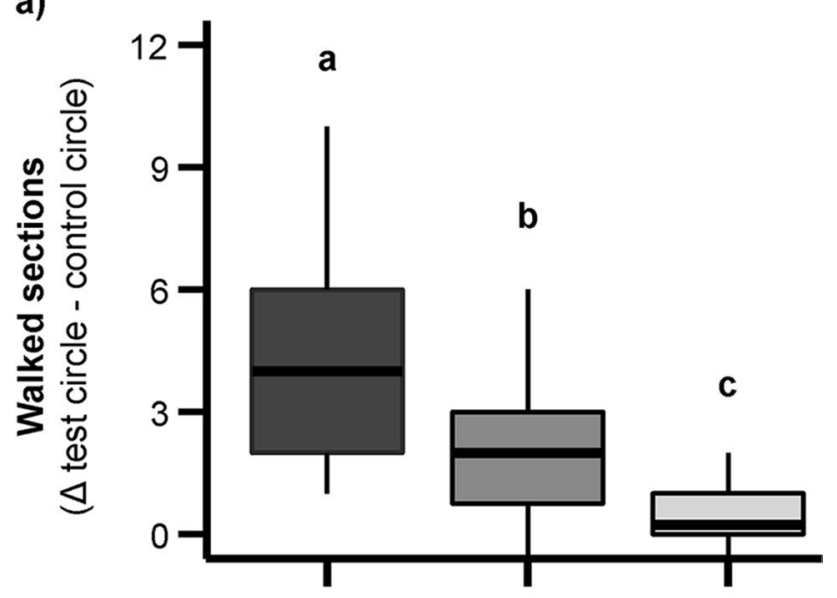

b)

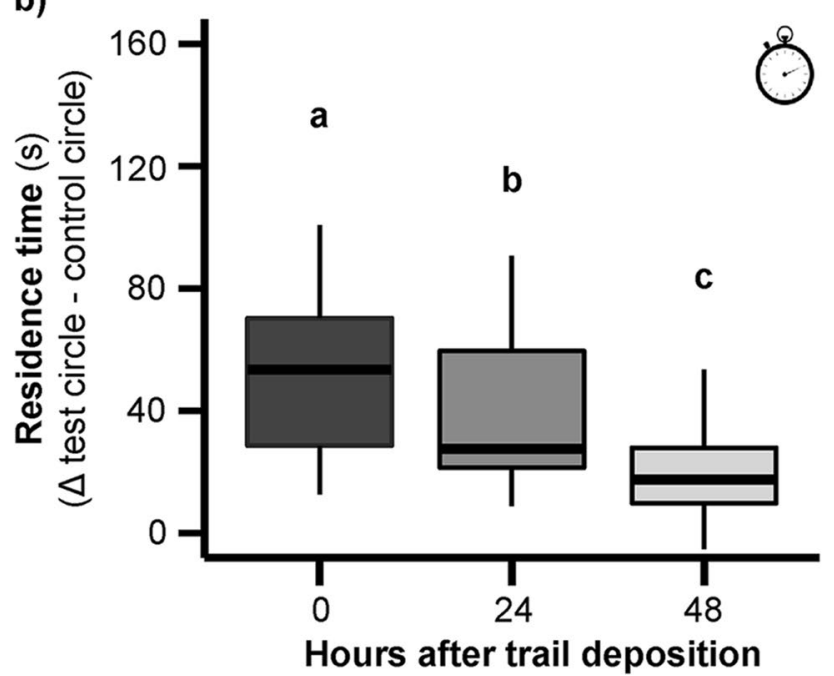

Fig. 3 Behavioral response of female Holepyris sylvanidis to trails consisting of non-sterile-filtered larval extracts of Tribolium confusum ( $5 \mathrm{LE}$ of $T$. confusum 4th instar larvae per trail). Circular trails were deposited $0 \mathrm{~h}, 24 \mathrm{~h}$, or $48 \mathrm{~h}$ before being offered to the parasitoids $(N=28$ per time interval). Mean differences $(\Delta)$ of a) walked sections and $\mathbf{b})$ residence time (indicated by the clock inset) on test and control circle at different time intervals are displayed. Test circle: hexane-extracted larval host trails. Control circle: hexane only. The parasitoid's trail-following activity at different time intervals was analyzed by a Kruskal-Wallis test followed by pairwise Wilcoxon's ranksum test with Bonferroni-Holm correction. Different letters indicate significant differences at $P<0.05$

efficiently perceivable. Consequently, the CHCs lost the ability to induce trail-following behavior in the parasitoid.

Liquid CHCs are expected to have a greater interorganismic, informative relevance than solid ones because of their higher vapor pressure (Menzel et al. 2019; Othmer and Conwell 1945). Thus, they might not only be perceivable upon contact and bind to the odorant-binding proteins in the olfactory sensilla but could also be detected over some distance via the gas phase. For example, ants can perceive long-chain

\section{Fresh and aged trails after re-dissolving}

a)

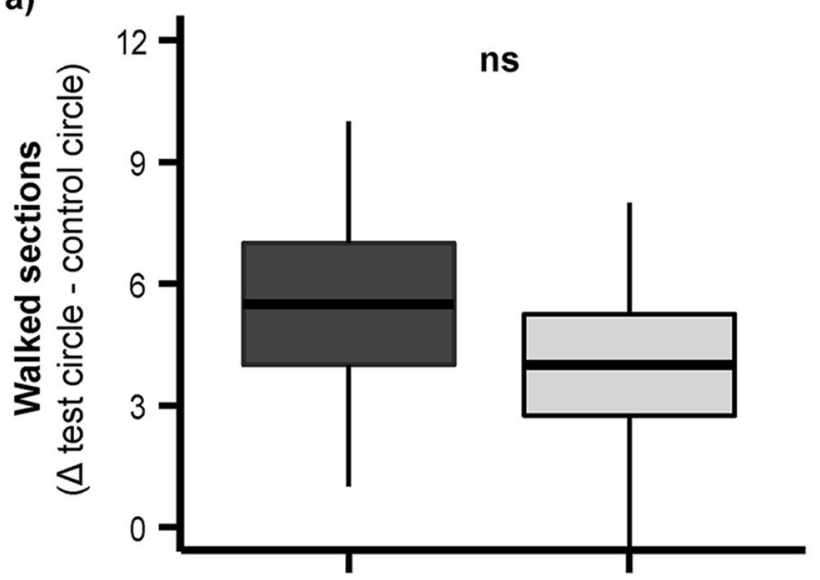

b)

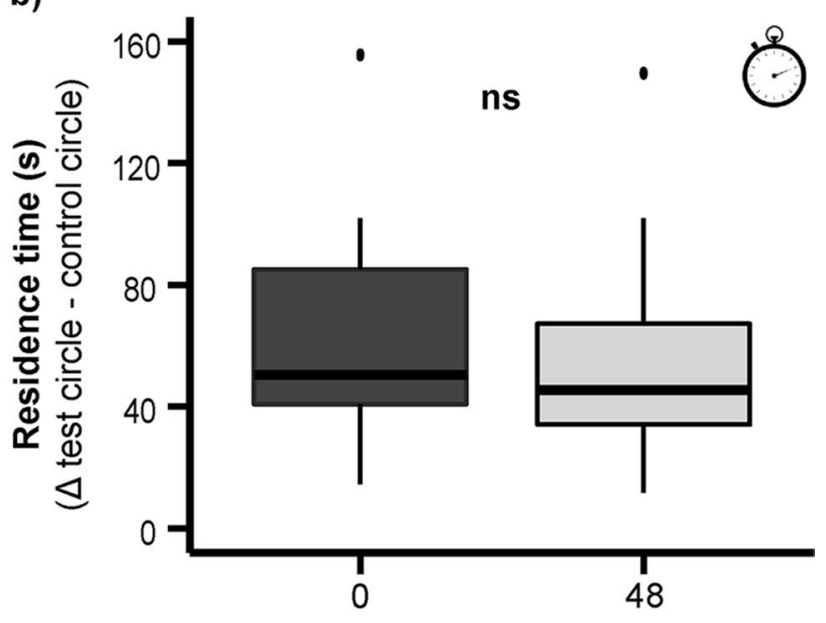

Hours after trail deposition

Fig. 4 Behavioral response of female Holepyris sylvanidis to hexaneredissolved trails from non-sterile-filtered larval extracts of Tribolium confusum (5 LE of $T$. confusum 4th instar larvae per trail). The circular trails were offered to the parasitoids as freshly laid trails $(0 \mathrm{~h})$ or $48 \mathrm{~h}$ after deposition. Both trail types had been re-dissolved with $\mathrm{n}$-hexane $(25 \mu \mathrm{l})$ prior to the beginning of the bioassays $(N=28$ per time interval). Test circle: hexane-extracted larval host trails. Control circle: hexane only. Mean differences $(\Delta)$ of a) walked sections and b) residence time (indicated by the clock inset) on test and control circle at different time points are displayed. The parasitoid's trail-following activity at different time intervals was analyzed by Student's $t$ - test or Wilcoxon's rank-sum test (ns $=$ not significant, $P>0.05$ )

CHCs for differentiation of nestmates and non-nestmates without physical contact from a distance of $1 \mathrm{~cm}$ (Brandstaetter et al. 2008). This indicates that long-chain CHCs are volatile at least to a certain extent. Since $H$. sylvanidis females follow CHC trails of $T$. confusum host larvae by zig-zag movements along the trail, they most probably can directly contact the trail components; however, perception over a short distance cannot be excluded. 


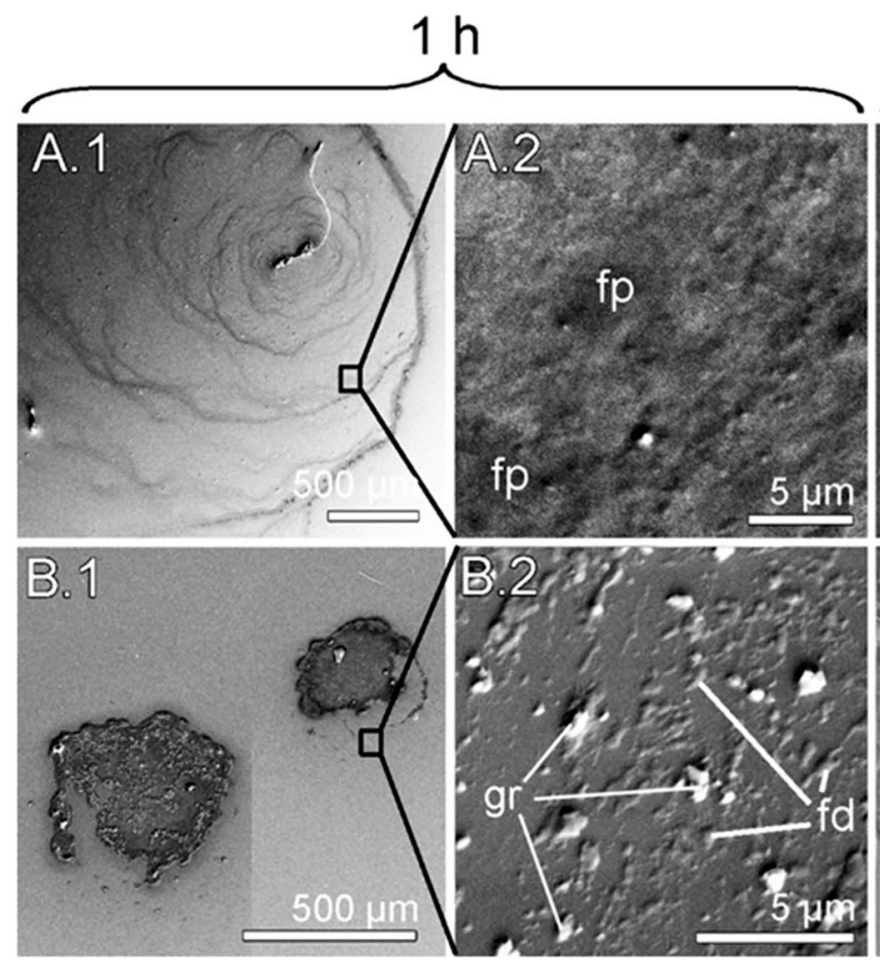

Fig. 5 Cryo-SEM images of non-sterile-filtered hexane extracts of Tribolium confusum larvae applied to polar (A.1-4) and apolar (B.14) silicon wafers. Photos were taken at different time intervals after release onto the substrate, i.e. after $1 \mathrm{~h}$ (A.1-2, B.1-2) and $48 \mathrm{~h}$ (A.34, B.3-4). Note the "coffee ring" pattern in A.1, thin fluid patches in A.2, solidified filaments in A.3, very thin, re-dissolved fluid patches

Due to their melting behavior, some mono- and dimethylbranched CHCs are expected to be liquid in freshly laid larval trails at ambient temperatures, whereas other monomethyl-branched alkanes might begin to solidify right after trail deposition (Brooks et al. 2015; Gibbs and Pomonis 1995). The liquid aggregate state of methyl-branched alkanes might be relevant for eliciting trail-following behavior in $\mathrm{H}$. sylvanidis. This suggestion is supported by our previous study, which showed that methyl-branched CHCs on the cuticle of T. confusum larvae are exploited by $H$. sylvanidis females for host recognition when directly contacting the host larvae (Awater-Salendo et al. 2020).

The sterile-filtered extracts were lacking some of those methyl-branched alkanes that were present in low quantities in the non-sterile trails, i.e. 3-MeC28, 5-MeC29, 5,X-DiMeC29, and 3,X-DiMeC29. We might have lost the low quantities of these compounds and $n$-C30 when filtering the larval extract through a sterile membrane. Despite the presence of these five compounds in non-sterile trails $24 \mathrm{~h}$ and $48 \mathrm{~h}$ after trail deposition, the kairomonal activity of these trails decreased significantly over time compared to freshly laid trails $(=0 \mathrm{~h})$, and almost no trail-following behavior by parasitoid females was observed after $48 \mathrm{~h}$. This

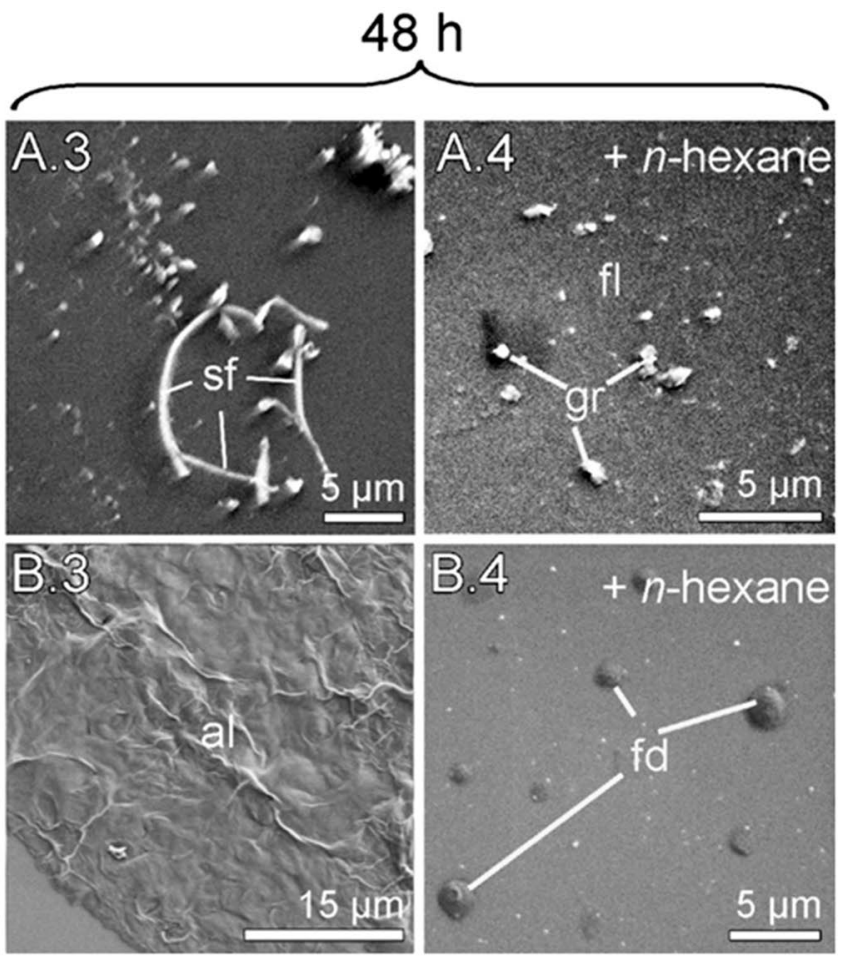

and granules in A.4, voluminous residues in B.1, tiny fluid droplets at the edges of larger patches in B.2, solidified amorphous films in B.3, and re-dissolved small fluid droplets in B.4. al, solidified, amorphous layer; fd, fluid droplets; fl, fluid layer; fp, fluid patches; sf, solidified filaments; gr, granules

suggests that these five long-chained CHCs are either not relevant in eliciting trail-following behavior of $H$. sylvanidis or they are no longer in a liquid phase at these time intervals past trail deposition, and thus not perceivable for the parasitoid.

Does also the substrate onto which T. confusum host larvae deposit their trails, affect the persistence of trail kairomonal activity? In the present study, we investigated host trails by applying larval cuticular extracts on inert glass ground, a polar substrate. This approach enabled us to determine possible shifts in the $\mathrm{CHC}$ profile over time since trails could be extracted from the glass for chemical analysis after distinct time intervals past deposition. Glass as substrate is very different from the natural substrates onto which $T$. confusum larvae release their trails. Larvae of this species are living where grains and further processed or refined plant and food products stored by humans are available. Thus, they release trails both onto polar substrates such as fine flour with all its carbohydrates, but also on whole grains with their often waxy, apolar surface. Our previous studies showed that the kairomonal activity of $T$. confusum trails naturally laid by larvae on course wheat grist (including seed coats, broken grain kernels) persisted as long as those trails extracted with 
hexane, i.e. $48 \mathrm{~h}$ past trail deposition (Fürstenau and Hilker 2017). Larval trails released by other insect species (coccinellid larvae, caterpillars) on natural substrates (leaves) are also known to elicit behavioral responses by braconid parasitoid species only for a maximum of two days past deposition. As in our study, these trails exclusively consist of long-chain CHCs with different structural features (Nakashima et al. 2004; Rostás and Wölfling 2009).

Under natural conditions, abiotic environmental factors might significantly influence the speed of transition from the liquid to solid state of CHCs. Especially temperature can significantly affect this transition (Gibbs 2002; Gibbs and Pomonis 1995). For instance, the different CHC profiles of several ant species became entirely liquid at temperatures ranging between $30{ }^{\circ} \mathrm{C}$ and $45^{\circ} \mathrm{C}$ (Menzel et al. 2019). Hence, it is likely that high temperatures retard the solidification process of CHCs of $T$. confusum larvae. If so, the larval trails would remain longer in the liquid state, and thus their kairomonal activity for parasitoids might last longer. Low temperatures, in contrast, have an opposite effect and accelerate solidification of CHCs. Accelerated solidification T. confusum $\mathrm{CHCs}$ possibly driven by low temperatures is expected to result in an earlier loss of the kairomonal activity of trails within two days at room temperature. We suggest that differences in ambient temperature lead to different behavioral responses of parasitoids to host trails consisting of CHCs.

If the loss of the informative activity of insects $\mathrm{CHCs}$ is caused by the solidification of the $\mathrm{CHC}$ blend, as suggested above for $T$. confusum trails, the question arises what keeps CHCs liquid or in a liquid-solid phase on the insect cuticle so that they are released in this physical state onto a substrate. Our study suggests that compounds not detectable in hexane extracts of insect CHCs are relevant for the physical state of CHCs on the insect's cuticle. Proteins in an aqueous medium are candidate compounds. They are known to function as $\mathrm{CHC}$ carriers, transporting the apolar $\mathrm{CHCs}$ through an aqueous medium from their synthesis site (e.g., the oenocytes) to the outer layer of the cuticle (Mohammadzadeh-K et al. 1969; Schal et al. 1998; Wigglesworth 1990). In addition, it is known for insect footprints, i.e. adhesion-mediating tarsal secretion, that they are formed by nanodroplets containing an apolar and a polar phase (Betz 2003; Hasenfuss 1977; Vötsch et al. 2002). The apolar phase often consists of a chemical blend whose hydrocarbon composition is often similar to that of the epicuticular grease, whereas water-soluble carbohydrates and proteins are assumed to be components of the polar phase (Geiselhardt et al. 2009, 2010; Gerhardt et al. 2016; Vötsch et al. 2002). The presence of proteinaceous components has been confirmed for tarsal fluids by Vötsch et al. (2002) and
Betz et al. (2016). Hence, proteins might be involved in processes, which prevent $\mathrm{CHCs}$ from adopting a folded conformation and from forming densely packed assemblages by intermolecular interactions. After deposition of a blend of CHCs and proteins onto a substrate, proteins would quickly denature, thus allowing the $\mathrm{CHCs}$ to interact. To further elucidate the cause of the loss of the kairomonal activity of larval trails, future studies should focus on both the polar and apolar chemical composition of the epicuticular grease of host larvae and their naturally laid trails.

Taken together, our study showed that the CHC blend of an insect trail does neither qualitatively nor quantitatively change within $48 \mathrm{~h}$ past trail deposition but loses its kairomonal activity for a parasitoid within this time interval. This result was independent of whether microbial degradation of trails had been excluded or not. Since a change in the $\mathrm{CHC}$ composition of the trail cannot be made responsible for the temporary kairomonal effect, our study rather suggests that $\mathrm{CHCs}$ present in their liquid phase in freshly laid host trails gradually form solid structures and thus become less perceptible (as host-indicating cues) for foraging parasitoids. Future studies need to further elucidate whether as yet unconsidered polar compounds contribute to the gradual loss of kairomonal activity of host larval CHC trails.

Supplementary Information The online version contains supplementary material available at https://doi.org/10.1007/s10886-021-01310-w.

Acknowledgments We dedicate this work to the memory of the so highly esteemed chemist Wittko Francke, who recently passed away. It was Wittko, who always accompanied our studies with his enormous enthusiasm for chemical ecology. He encouraged us to investigate whether the short persistence of the kairomonal activity of the CHC trails of $T$. confusum is due to microbial degradation. We thank Arne Weinhold (Freie Universität Berlin, Germany) for supporting the preparation of sterile-filtered extracts. Furthermore, many thanks are due to Tobias Hoffmann (Julius Kühn Institute, Berlin, Germany) for his help in rearing the insects and to Raphael Büchner and Rene Grünwald for technical assistance in the chemical analysis of trails. Dagmar Voigt thanks the Free State of Saxony (project BIOS) for financial support and Professor Christoph Neinhuis, the Chair of Botany at the faculty of Biology of TU Dresden (Germany) for providing access to cryo-SEM. We also thank two anonymous reviewers for their helpful comments on an earlier draft of the manuscript.

Authors' Contributions S.A.S., M.H., and B.F. contributed to the study conception and design. Material preparation, data collection, and analysis were performed by S.A.S. (bioassays and chemical analysis) and D.V. (cryo-SEM). The first draft of the manuscript was written by S.A.S. B.F. and M.H. revised it, and all authors commented on previous versions of the manuscript. All authors read and approved the final manuscript.

Funding Research by Dagmar Voigt was financially supported by Free State of Saxony (project BIOS). Open Access funding enabled and organized by Projekt DEAL. 
Data Availability Datasets generated in the current study are available upon request via the corresponding author.

Code Availability Coding in " $\mathrm{R}$ " used in the current study is available upon request via the corresponding author.

\section{Declarations}

Ethics Approval Not applicable.

Consent to Participate Not applicable.

Consent for Publication Not applicable. Additional Declarations for Articles in Life Science Journals that Report the Results of Studies Involving Humans and/or Animals Not applicable.

Conflicts of Interest/Competing Interests The authors have no conflicts of interest to declare that are relevant to the contents of this article.

Open Access This article is licensed under a Creative Commons Attribution 4.0 International License, which permits use, sharing, adaptation, distribution and reproduction in any medium or format, as long as you give appropriate credit to the original author(s) and the source, provide a link to the Creative Commons licence, and indicate if changes were made. The images or other third party material in this article are included in the article's Creative Commons licence, unless indicated otherwise in a credit line to the material. If material is not included in the article's Creative Commons licence and your intended use is not permitted by statutory regulation or exceeds the permitted use, you will need to obtain permission directly from the copyright holder. To view a copy of this licence, visit http://creativecommons.org/licenses/by/4.0/.

\section{References}

Amante M, Schöller M, Suma P, Russo A (2017) Bethylids attacking stored-product pests: an overview. Entomol Exp Appl 163:251264. https://doi.org/10.1111/eea.12587

Amante M, Russo A, Schöller M, Steidle JLM (2018) Olfactory host location and host preference of Holepyris sylvanidis (Brèthes) (Hymenoptera: Bethylidae), a parasitoid of Tribolium confusum Jacquelin du Val and T. castaneum (Herbst) (Coleoptera: Tenebrionidae). J Stored Prod Res 78:105-109. https://doi.org/10. 1016/j.jspr.2018.06.008

Awater-Salendo S, Schulz H, Hilker M, Fürstenau B (2020) The importance of methyl-branched cuticular hydrocarbons for successful host recognition by the larval ectoparasitoid Holepyris sylvanidis. J Chem Ecol 46:1032-1046. https://doi.org/10.1007/ s10886-020-01227-w

Beament JWL (1958) The effect of temperature on the water-proofing mechanism of an insect. J Exp Biol 35:494-519

Bernal JS, Luck RF (2007) Mate finding via a trail sex pheromone by Aphytis melinus DeBach (Hymenoptera: Aphelinidae) males. J Insect Behav 20:515-525. https://doi.org/10.1007/ s10905-007-9092-1

Betz O (2003) Structure of the tarsi in some Stenus species (Coleoptera, Staphylinidae): external morphology, ultrastructure, and tarsal secretion. J Morphol 255:24-43. https://doi.org/10.1002/ jmor. 10044

Betz O, Maurer A, Verheyden AN, Schmitt C, Kowalik T, Braun J, Grunwald I, Hartwig A, Neuenfeldt M (2016) First protein and peptide characterization of the tarsal adhesive secretions in the desert locust, Schistocerca gregaria, and the Madagascar hissing cockroach, Gromphadorhina portentosa. Insect Mol Biol 25:541-549. https://doi.org/10.1111/imb.12241

Blomquist GJ, Bagnères AG (2010) Insect hydrocarbons: biology, biochemistry, and chemical ecology. Cambridge University Press, Cambridge

Blomquist GJ, Ginzel MD (2021) Chemical ecology, biochemistry, and molecular biology of insect hydrocarbons. Annu Rev Entomol 66:45-60. https://doi.org/10.1146/annurev-ento-031620-071754

Borges M, Colazza S, Ramirez-Lucas P, Chauhan KR, Moraes MCB, Richard Aldrich J (2003) Kairomonal effect of walking traces from Euschistus heros (Heteroptera: Pentatomidae) on two strains of Telenomus podisi (Hymenoptera: Scelionidae). Physiol Entomol 28:349-355. https://doi.org/10.1111/j.1365-3032.2003. 00350.x

Brandstaetter AS, Endler A, Kleineidam CJ (2008) Nestmate recognition in ants is possible without tactile interaction. Naturwissenschaften 95:601-608. https://doi.org/10.1007/s00114-008-0360-5

Brooks L, Brunelli M, Pattison P, Jones GR, Fitch A (2015) Crystal structures of eight mono-methyl alkanes (C 26 - C 32) via singlecrystal and powder diffraction and DFT-D optimization. IUCrJ 2:490-497. https://doi.org/10.1107/S2052252515010271

Clarke KR (1993) Non-parametric multivariate analyses of changes in community structure. Aust J Ecol 18:117-143. https://doi.org/10. 1111/j.1442-9993.1993.tb00438.x

Colazza S, Aquila G, De Pasquale C, Peri E, Millar JG (2007) The egg parasitoid Trissolcus basalis uses $n$-nonadecane, a cuticular hydrocarbon from its stink bug host Nezara viridula, to discriminate between female and male hosts. J Chem Ecol 33:1405-1420. https://doi.org/10.1007/s10886-007-9300-7

Colazza S, Lo Bue M, Lo Giudice D, Peri E (2009) The response of Trissolcus basalis to footprint contact kairomones from Nezara viridula females is mediated by leaf epicuticular waxes. Naturwissenschaften 96:975-981. https://doi.org/10.1007/ s00114-009-0548-3

Colazza S, Cusumano A, Lo Giudice D, Peri E (2014) Chemo-orientation responses in hymenopteran parasitoids induced by substrateborne semiochemicals. BioControl 59:1-17. https://doi.org/10. 1007/s10526-013-9546-7

Core Team R (2020) R: a language and environment for statistical computing. R Foundation for Statistical Computing, Vienna, Austria

Deegan RD, Bakajin O, Dupont TF, Huber G, Nagel SR, Witten TA (1997) Capillary flow as the cause of ring stains from dried liquid drops. Nature 389:827-829. https://doi.org/10.1038/39827

Deegan RD, Bakajin O, Dupont TF, Huber G, Nagel SR, Witten TA (2000) Contact line deposits in an evaporating drop. Phys Rev E 62:756-765. https://doi.org/10.1103/PhysRevE.62.756

Dexter E, Rollwagen-Bollens G, Bollens SM (2018) The trouble with stress: a flexible method for the evaluation of nonmetric multidimensional scaling. Limnol Oceanogr Methods 16:434-443. https://doi.org/10.1002/lom3.10257

Engl T, Kaltenpoth M (2018) Influence of microbial symbionts on insect pheromones. Nat Prod Rep 35:386-397. https://doi.org/10. 1039/C7NP00068E

Evans HE (1969) A revision of the genus Holepyris in the Americas (Hymenoptera: Bethylidae). Trans Am Entomol Soc 95:181-209

Fürstenau B, Hilker M (2017) Cuticular hydrocarbons of Tribolium confusum larvae mediate trail following and host recognition in the ectoparasitoid Holepyris sylvanidis. J Chem Ecol 43:858-868. https://doi.org/10.1007/s10886-017-0885-1

Fürstenau B, Adler C, Schulz H, Hilker M (2016) Host habitat volatiles enhance the olfactory response of the larval parasitoid Holepyris sylvanidis to specifically host-associated cues. Chem Senses 41:611-621. https://doi.org/10.1093/chemse/bjw065 
Geiselhardt SF, Geiselhardt S, Peschke K (2009) Comparison of tarsal and cuticular chemistry in the leaf beetle Gastrophysa viridula (Coleoptera: Chrysomelidae) and an evaluation of solid-phase microextraction and solvent extraction techniques. Chemoecology 19:185-193. https://doi.org/10.1007/s00049-009-0021-y

Geiselhardt SF, Lamm S, Gack C, Peschke K (2010) Interaction of liquid epicuticular hydrocarbons and tarsal adhesive secretion in Leptinotarsa decemlineata say (Coleoptera: Chrysomelidae). J Comp Physiol A Neuroethol Sensory, Neural, Behav Physiol 196:369-378. https://doi.org/10.1007/s00359-010-0522-8

Gerhardt H, Betz O, Albert K, Lämmerhofer M (2016) Insect adhesion secretions: similarities and dissimilarities in hydrocarbon profiles of tarsi and corresponding tibiae. J Chem Ecol 42:725-738. https://doi.org/10.1007/s10886-016-0718-7

Gibbs AG (1998) Water-proofing properties of cuticular lipids. Am Zool 38:471-482. https://doi.org/10.1093/icb/38.3.471

Gibbs AG (2002) Lipid melting and cuticular permeability: new insights into an old problem. J Insect Physiol 48:391-400. https:// doi.org/10.1016/S0022-1910(02)00059-8

Gibbs AG, Pomonis JG (1995) Physical properties of insect cuticular hydrocarbons: the effects of chain length, methyl-branching and unsaturation. Comp Biochem Physiol Part B Biochem Mol Biol 112:243-249. https://doi.org/10.1016/0305-0491(95)00081-X

Gomes Lagôa AC, Blassioli Moraes MC, Borges M, Laumann RA (2020) Selective responses of Trissolcus basalis and Telenomus podisi to chemical footprints of preferred hosts. Physiol Entomol 45:60-71. https://doi.org/10.1111/phen.12316

Hammer Ø, Harper D, Ryan P (2001) PAST: paleontological statistics software package for education and data analysis. Palaeontol Electron 4:1-9

Hasenfuss I (1977) Die Herkunft der Adhäsionsflüssigkeit bei Insekten. Zoomorphologie 87:51-64. https://doi.org/10.1007/BF02568741

Hilker M, McNeil J (2008) Chemical and behavioral ecology in insect parasitoids: how to behave optimally in a complex odorous environment. In: Behavioral ecology of insect parasitoids. Blackwell Publishing Ltd, Oxford, UK, pp 92-112

Howard RW, Blomquist GJ (2005) Ecological, behavioral, and biochemical aspects of insect hydrocarbons. Annu Rev Entomol 50:371-393. https://doi.org/10.1146/annurev.ento.50.071803. 130359

Howard RW, Flinn PW (1990) Larval trails of Cryptolestes ferrugineus (Coleoptera: Cucujidae) as kairomonal host-finding cues for the parasitoid Cephalonomia waterstoni (Hymenoptera: Bethylidae). Ann Entomol Soc Am 83:239-245. https://doi.org/10.1093/aesa/ 83.2.239

Howard RW, Charlton M, Charlton RE (1998) Host-finding, host-recognition, and host-acceptance behavior of Cephalonomia tarsalis (Hymenoptera: Bethylidae). Ann Entomol Soc Am 91:879-889. https://doi.org/10.1093/aesa/91.6.879

Jeanson R, Ratnieks FLW, Deneubourg J-L (2003) Pheromone trail decay rates on different substrates in the Pharaoh's ant, Monomorium pharaonis. Physiol Entomol 28:192-198. https://doi.org/10. 1046/j.1365-3032.2003.00332.x

Kapranas A, Lo GD, Peri E, Millar JG, Colazza S (2013) Emergence, dispersal, and mate finding via a substrate-borne sex pheromone in the parasitoid Metaphycus luteolus. Entomol Exp Appl 148:7483. https://doi.org/10.1111/eea.12077

Lecuona R, Riba G, Cassier P, Clement JL (1991) Alterations of insect epicuticular hydrocarbons during infection with Beauveria bassiana or B. brongniartii. J Invertebr Pathol 58:10-18. https://doi. org/10.1016/0022-2011(91)90156-K

Lo Giudice D, Riedel M, Rostás M, Peri E, Colazza S (2011) Host sex discrimination by an egg parasitoid on Brassica leaves. J Chem Ecol 37:622-628. https://doi.org/10.1007/s10886-011-9957-9
Lockey KH (1988) Lipids of the insect cuticle: origin, composition and function. Comp Biochem Physiol Part B Comp Biochem 89:595645. https://doi.org/10.1016/0305-0491(88)90305-7

Maroncelli M, Qi SP, Strauss HL, Snyder RG (1982) Nonplanar conformers and the phase behavior of solid n-alkanes. J Am Chem Soc 104:6237-6247. https://doi.org/10.1021/ja00387a013

Menzel F, Blaimer BB, Schmitt T (2017) How do cuticular hydrocarbons evolve? Physiological constraints and climatic and biotic selection pressures act on a complex functional trait. Proc R Soc B Biol Sci 284:20161727. https://doi.org/10.1098/rspb.2016.1727

Menzel F, Morsbach S, Martens JH, Räder P, Hadjaje S, Poizat M, Abou B (2019) Communication versus waterproofing: the physics of insect cuticular hydrocarbons. J Exp biol 222:jeb210807. https://doi.org/10.1242/jeb.210807

Mohammadzadeh-K A, Feeney RE, Smith LM (1969) Hydrophobic binding of hydrocarbons by proteins. I Relationship of hydrocarbon structure. Biochim Biophys Acta - Protein Struct 194:246255. https://doi.org/10.1016/0005-2795(69)90200-1

Morgan ED (2009) Trail pheromones of ants. Physiol Entomol 34:117. https://doi.org/10.1111/j.1365-3032.2008.00658.x

Nakashima Y, Birkett MA, Pye BJ, Pickett JA, Powell W (2004) The role of semiochemicals in the avoidance of the seven-spot ladybird, Coccinella septempunctata, by the aphid parasitoid, Aphidius ervi. J Chem Ecol 30:1103-1116. https://doi.org/10.1023/B: JOEC.0000030266.81665.19

Napolitano R, Juárez MP (1997) Entomopathogenous fungi degrade epicuticular hydrocarbons of Triatoma infestans. Arch Biochem Biophys 344:208-214. https://doi.org/10.1006/abbi.1997.0163

Niemietz A, Wandelt K, Barthlott W, Koch K (2009) Thermal evaporation of multi-component waxes and thermally activated formation of nanotubules for superhydrophobic surfaces. Prog Org Coatings 66:221-227. https://doi.org/10.1016/j.porgcoat.2009.07.009

Oksanen J, Blanchet FG, Friendly M, Kindt R, Legendre P, McGlinn D, Minchin RP, O'Hara RB, Simpson GL, Solymos P, et al (2019) Vegan: community ecology package (version 2.5-6). https://cran.rproject.org/package $=$ vegan

Othmer DF, Conwell JW (1945) Correlating viscosity and vapor pressure of liquids. Ind Eng Chem 37:1112-1115. https://doi.org/10. 1021/ie50431a027

Otte T, Hilker M, Geiselhardt S (2018) Phenotypic plasticity of cuticular hydrocarbon profiles in insects. J Chem Ecol 44:235-247. https://doi.org/10.1007/s10886-018-0934-4

Ozaki M, Wada-Katsumata A (2010) Perception and olfaction of cuticular compounds. In: Blomquist GJ, Bagneres AG (eds) Insect hydrocarbons: biology, biochemistry, and chemical ecology. Cambridge University Press, Cambridge, pp 207-221

Pedrini N, Ortiz-Urquiza A, Huarte-Bonnet C, Zhang S, Keyhani NO (2013) Targeting of insect epicuticular lipids by the entomopathogenic fungus Beauveria bassiana: hydrocarbon oxidation within the context of a host-pathogen interaction. Front Microbiol 4:118. https://doi.org/10.3389/fmicb.2013.00024

Robinson EJH, Green KE, Jenner EA, Holcombe M, Ratnieks FLW (2008) Decay rates of attractive and repellent pheromones in an ant foraging trail network. Insect Soc 55:246-251. https://doi.org/ 10.1007/s00040-008-0994-5

Rostás M, Wölfling M (2009) Caterpillar footprints as host location kairomones for Cotesia marginiventris: persistence and chemical nature. J Chem Ecol 35:20-27. https://doi.org/10.1007/ s10886-009-9590-z

Salerno G, Frati F, Conti E, De Pasquale C, Peri E, Colazza S (2009) A finely tuned strategy adopted by an egg parasitoid to exploit chemical traces from host adults. J Exp Biol 212:1825-1831. https://doi.org/10.1242/jeb.028308

Schal C, Sevala VL, Young HP, Bachmann JAS (1998) Sites of synthesis and transport pathways of insect hydrocarbons: cuticle and 
ovary as target tissues. Am Zool 38:382-393. https://doi.org/10. 1093/icb/38.2.382

Sprenger PP, Menzel F (2020) Cuticular hydrocarbons in ants (Hymenoptera: Formicidae) and other insects: how and why they differ among individuals, colonies, and species. Myrmecological news 30:1-26. https://doi.org/10.25849/myrmecol.news_030:001

Sprenger PP, Burkert LH, Abou B, Federle W, Menzel F (2018) Coping with the climate: cuticular hydrocarbon acclimation of ants under constant and fluctuating conditions. J Exp biol 221:jeb171488. https://doi.org/10.1242/jeb.171488

Steidle JLM, Van Loon JJA (2003) Dietary specialization and infochemical use in carnivorous arthropods: testing a concept. Entomol Exp Appl 108:133-148. https://doi.org/10.1046/j.1570-7458. 2003.00080.x

Van den Dool H, Kratz PD (1963) A generalization of the retention index system including linear temperature programmed gas-liquid partition chromatography. J Chromatogr A 11:463471. https://doi.org/10.1016/S0021-9673(01)80947-X

Vinson SB (1998) The general host selection behavior of parasitoid hymenoptera and a comparison of initial strategies utilized by larvaphagous and oophagous species. Biol Control 11:79-96. https://doi.org/10.1006/bcon.1997.0601

Vötsch W, Nicholson G, Müller R, Stierhof Y-D, Gorb S, Schwarz U (2002) Chemical composition of the attachment pad secretion of the locust Locusta migratoria. Insect Biochem Mol Biol 32:16051613. https://doi.org/10.1016/S0965-1748(02)00098-X

Wigglesworth VB (1990) The distribution, function and nature of "cuticulin" in the insect cuticle. J Insect Physiol 36:307-313. https://doi.org/10.1016/0022-1910(90)90011-4 